XX.

Aus der II. chirurgischen Universitätsklinik zu Wien.

(Vorstand: Hofrat Prof. Dr. J. Hochenegg.)

\title{
Zur Statistik der Gastroenterostomien bei benignen Magenerkrankungen.
}

Ein historischer Rückblick. Von

Dr. O. E. Schulz, Operatenrzögling and Demonstrator.

Gelegentlich der Operation eines Magencarcinoms hat. wegen Inoperabilität desselben, Wölfler im September 1881 an der II. chir. Klinik in Wien auf Initiative Nicoladonis hin eine Kommunikation zwischen Magen und Dünndarm angelegt, um so den durch das Carcinom bedingten Stenoseerscheinungen zu begegnen. Die erste Gastroenterostomie (Gastroenterorrhaphie) (27. IX. 1881). 1)

In dem Vierteljahrhundert, das seitdem vergangen ist, hat diese Operation bedeutende Veränderungen ihrer ursprünglichen Technik erfahren, hat diese Operation aber auch so viel Heil und Segen gespendet, daß es der Mühe wert erscheint, einen Rückblick auf ihre Entwicklung zu werfen und die durch dieselbe erzielten Heilerfolge zu berücksichtigen. Technische Fehler, Nachteile in der Methode führten seit Wölflers erster Gastroenterostomie zu immer neuen Änderungen in der operativen Technik, zu Modifikationen, von denen manche in Bälde wieder verlassen, durch ungünstige Resultate anderer widerlegt, ihre Berechtigung verloren haben und heute nur mehr historisches Interesse verdienen. Schon der zweite nach Wölflers Methode operierte Fall endete letal unter den später wohlbekannten und mit Recht gefürchteten Symptomen des Circulus vitiosus. Die Ursache dieser gefährlichen, in ausgesprochenen Fällen

1) Die Angabe 27. IX. ist laut Krankengeschichte die authentisch richtige. 
Zur Statistik der Gastroenterostomien bei benignen Magenerkrankungen. 495

stets letal verlanfenden Komplikation wurde darin gesucht, daß durch Knickung der zur Anastomose verwendeten Schlingen, durch Parallellagerung beider Schenkel oder durch Spornbildung aus der mesenteriellen der Anastomosenöffnung gegenüberliegenden Wand ein ventilartiger oder strangulierender Verschluß der aboralen Schlinge zustande käme, wodurch der Mageninhalt in die zuführende Schlinge sich entleere. Andererseits machte sich die Vorstellung geltend, daß die den Mageninhalt von links nach rechts vorwärtsbewegende Magenperistaltik an der Anastomosenöfnung zu einem Punkte gelangt, an dem die peristaltische Welle verkehrt verläuft. Ein anderes Moment war die Füllung der adoralen Schlinge mit Magencontentis trotz, wenigstens im Anfang, nicht behinderter Permeabilität der aboralen Schlinge. Der Zufluß von Galle in den Magen, Störungen im Ablauf der Peristaltik wurden als Ursachen des Circulus vitiosus betrachtet. Die verschiedenen Formen des Circulus vitiosus (Tavel) ${ }^{1}$ ), die verschieden nach Verlauf und Obduktionsbefund waren, führten zu neuen Theorien und Auffassungen dieser Komplikation und dementsprechend zu Änderungen in der Technik der Gastroenterostomie.

Die Modifikation der isoperistaltischen Lagerung der zur Anastomose verwendeten Schlinge (Lücke-Rockwitz), die Enteroanastomose nach Braun - der übrigens trotz isoperistaltischer Lagerung die Entstehung eines Circulus vitiosus sah - eigene Anastomosenknöpfe (Villard, Jaboulay, Doyen) mit seitlichem in das abführende Darmlumen mündendem Ausführungsrohr (Fritz de Beule), alle diese Methoden hatten nur den Endzweck, dem Circulus vitiosus vorzubeugen. Kocher ersann hierzu seine Methode der Ventilbildung, Rutkowsky kombinierte die Gastroenterostomie mit einer Gastrostomie und führte durch die letztere ein Drainrohr in die aborale Schlinge. Kapeller suspendierte beide Schlingen durch Nähte an der Magenwand, eine Methode, die früher schon von Brenner ausgeführt wurde, mußte aber trotzdem wegen eines Circulus vitiosus in einer Relaparotomie zur Braunschen Enteroanastomose zurückkehren. Roux bezw. Wölfler führten die Y-förmige Gastroenterostomie ein, die von Lücke im Sinne einer isoperistaltischen Schlingenlagerung modifiziert wurde, und ein Analogon in der $\mathrm{Me}$ thode von Chaput hat. Föderl, um einer Parallellagerung beider vorzubeugen, verkürzte das Mesenterium knapp an der Anastomosenöffnung, während v. Hacker wiederum den zuführenden Schenkel

1) Nach Fritz de Beule. 
durch Nähte verengte. Jede dieser neuen Methoden brachte vielfach Besserungen, vervollkommnete die Technik, die meisten aber konnten sich in weitem Kreise keine absolnte unbestrittene Anerkennung verschaffen. Alle diese Veränderungen in der ursprünglichen Methode entstanden aus der begründeten Furcht vor dem Circulus vitiosus, dem Reflux der Franzosen, und wurden bald für die vordere, bald für die hintere Gastroenterostomie empfohlen. -

Die Methode Wölflers, von der ihr Autor in begründeter Voraussicht sagte, daß sie berufen sei, bei Carcinom des Pylorus Erleichterung, bei narbiger Stenose Heilung zu b ringen, hat ja zweifellos gewisse Nachteile. Die zur Anastomose verwendete Schlinge muß lang, entschieden länger sein, als bei der v. Hackerschen Methode. Wählt man sie recht kurz, so kann es zur Kompression des Quercolon und zur Darmstenose kommen (Miknlicz, Haberkant), besonders dann, wenn der Magen, wieder suffizient geworden, sich allmählich verkleinert; durch das Gewicht des emporgeschlagenen Netzes wiederum werden die beiden Dünndarmschlingen nach abwärts gezogen und leicht in Parallelstellung gebracht. Zur Vermeidung dessen empfahl Buomo, die Netzschürze in ihrem Mittelstück aufzuraffen und an die vordere Magenwand anzunähen. Allgemein wurde eine $50 \mathrm{~cm}$ lange Schlinge empfohlen. Auch diese konnte bei sehr dilatiertem Magen zu kurz sein, war sie aber zu lang, so konnte sie den Anlaß bieten zu einer inneren Incarceration. Dazu kommt die Vorstellung der mechanischen Entleerungsbedingungen, die bei vorderer Anastomose für den stehenden Menschen ungünstig sind. Dies veranlaßte Roux zu dem wohl allzu scharfen Ausspruch: „Die vordere Gastroenterostomie ist fehlerhaft in sich selbst, denn diejenigen, die ihrer bedürfen, sind nicht imstande, herum zu gehen."

So verdanke ich privater Mitteilung die Krankengeschichte folgenden Falles. Ein Pat. war wegen Ulcusbeschwerden nach Wölflers Methode operiert worden. Relativ beschwerdefrei klagte er doch stets mehrere Stunden nach dem Essen, besonders nach der Hauptmahlzeit, über ein unangenehmes Druckgefühl im Magen. Als eifriger Billardspieler machte er bei sogenannten langen Stößen, wenn er sich stark utber das Brett bücken mußte, die Beobachtung, eine bedeutende Erleichterung unter plötzlichem Gefühl der Entlastung zu spüren. In der Folge benützte er immer eine stark nach vorne gebtickte Lage, wenn er Beschwerden nach einer reichlichen Hauptmahlzeit empfand.

Die zweite Art der Gastroenterostomie, die v. Hackersche Methode, kann bei unrichtiger Wahl der Schlinge ebenfalls zu bedeutenden Beschwerden führen. Von Courvoisier bereits vor 
Hacker, allerdings mit ungünstigem, durch Colongangrän bedingten Resultat versucht, repräsentiert sie wohl heute meist das Normalverfahren (Kappeler 1898) in einer Form, die besonders von Petersen empfohlen, aber bereits früher von Hochenegg geübt wurde. Diese vor kurzem wieder als das beste Verfahren vorgeschlagene Gastroenterostomie entspricht am ehesten den normalen topographisch-anatomischen Verhältnissen. Lorenz hat darauf hingewiesen, daß bereits Porges (1897) früher als Petersen (1901) diese Art der Dünndarmanlagerung aus Hocheneggs poliklinischer Abteilung veröffentlichte. ${ }^{1}$ )

Zur Sicherung und rascheren Ausführung der Anastomose wurde nicht nur der Murphyknopf mit seiner von der Klinik Czerny empfohlenen Modifikation, sondern auch resorbierbare Knöpfe (Kelling) angewendet. Platten aus verschiedenstem Material, aus Gummi (Penrose), Kohlrüben (Baracz), Silber (Credé) sollten dazu dienen, die zwischen den beiden zu anastomosierenden Schlingen belassene Schleimhautbrücke durchzuquetschen. Um das Ausfließen von Magendarminhalt zu vermeiden, sind verschiedene Methoden angegeben worden, die alle darin gipfeln, nach Anlegen der Serosanähte die durch Incision bloßgelegte Mucosa zum Absterben zu bringen. Souligonx, Chaput, Bastianelli verätzten die Schleimhaut, wie es neuerdings Tatsujiro-Sato empfohlen hat, Boari nähte beide Serosaflächen zusammen, nachdem er vorher zwischen die beiden sich berührenden Mucosaflächen Tabletten aus kaustischen Substanzen legte, Postnikow zog die Schleimhaut zipfelförmig vor und brachte sie durch elastische Ligatur zur. Gangrän, Podres nähte Magen und Darm mit gekreuzten Schleimhautnähten aneinander, Porta, Modlinski und Meyer. (Mc Graw) benutzten hier-. zu dünne Gummifäden; Sykow eröffnete durch einen kleinen Schnitt vom Darm aus die aneinander genähten Lumina. Teils an Tieren im Experiment, teils auch an Patienten versucht, sind alle diese Methoden als unsicher, ja als gefährlich, teilweise als jedem chirurgischen Handeln widersprechend zu bezeichnen. Während der Drucklegung dieser Arbeit erschien eine Arbeit von Flint, der durch

1) Neuerdings wurde von Delaloye die antiperistaltische Lagerung ebenso für die vordere Gastroenterostonie empfohlen und auf eine 8 jährige Erfahrung mit dieser Methode verwiesen. Die anatomische Begründung, die bei der hinteren Gastroenterostomie der Methode der antiperistaltischen Lagerung ihre wesentliche Stütze verleiht, fällt hier weg. Trotzdem scheinen die Erfahrungen Delaloyes seine Empfehlung als berechtigt darzustellen. 
eine eigene zarte Darmschere, welche zwischen Magen und Darm eingenäht wird, die Lumina eröffnet.

Als eine Fortsetzung der Arbeit Exners, die das Material der Klinik bis zum Oktober 1903 umfaßte, habe ich es unternommen, die seit dem Erscheinen derselben ausgeführten Gastroenterostomien einer Kritik und Nachprüfung zu unterziehen und das im Laufe der Zeit gewonnene und aufgestapelte Krankenmaterial statistisch zu verwerten. Es wurden dabei, den Anforderungen Stichs ) (folgend, jene Fälle, bei denen ein Carcinom den Anlaß zur Anlegung einer Magendarmfistel bot, aus dem Bereiche dieser Untersuchungen weggelassen. Das Schicksal aller dieser Fälle ist klar und durch zahlreiche Statistiken genügend erörtert, und wenn auch einzelne Gastroenterostomien wegen Carcinom, dank günstiger äußerer Einflüsse, eine auf Jahre sich erstreckende leidliche Besserung ihres Zustandes zu verzeichnen haben, so ist doch schließlich der Tragik des endlichen Ausganges kein Halt geboten. So berichtet Schönholzer über einen Fall, der 600 Tage nach der Gastroenterostomie in leidlichem Wohlbefinden verbrachte, im Mittel wird aber das Resultat bis zum letalen Exitus mit zirka 200 Tagen angegeben. Andere Beobachtungen von 50, 54, 44 Monaten (Czerny), von 3 Jahren (Alsberg), 2 Jahren (Lauenstein) begründen nur die ausnahmsweise günstigen Resultate und beweisen die Berechtigung einer palliativen Operation. ${ }^{2}$ )

Viel mehr Interesse verdienen die Resultate der operativen Behandlung gutartiger Erkrankungen des Magens, die zuerst von Rydigier ausgeführte Resektion des Ulcus ventriculi, hauptsächlich aber die zuerst von ihm und Monatstyrski geübte Gastroenterostomie beim Magengeschwür.

Wenn bei den malignen Erkrankungen des Magens die interne Therapie - wenigstens gegenwärtig - dem Leiden machtlos gegenübersteht, und derartige Kranke, soweit sie noch operabel sind, nur beim Chirurgen ihr Heil suchen, bereits inoperabel, nur durch ihn Besserung finden können, gehört das Magengeschwür und seine

1) "Wir müssen, sagt Stich, die Forderung aufstellen, daß in Zukunft nicht in erster Linie Fälle von stenosierendem Krebs in der Statistik der Gastroenterostomien den hervorragenden Platz einnehmen, sonderu, daß die gutartigen und dauernd heilbaren Affektionen das Hauptkontigent hierzu stellen. Die niedrige Sterblichkeitsziffer und die günstigen Erfolge bei benignen Erkrankungen geben uns das Recht dazu."

2) Von den von meinem Chef, Prof. Hochenegg, wegen Ca. ventriculi gastroenterostomierten, lebt einer der Fälle, der am 23. IX. 1902 operiert wurde, heute noch, 4 Jahre nach der Operation. 
Zur Statistik der Gastroenterostomien bei benignen Magenerkrankungen. 499

Folgezustände zu den Grenzgebieten und man kann sagen, zu den umstrittenen Grenzgebieten der Medizin und Chirurgie. Zum Teil heute noch. Dementsprechend ist es begreiflich, daß sowohl Internisten als auch Chirurgen im Interesse um dieses Thema zum Worte sich meldeten, und eine stattliche Zahl von Arbeiten sich mit der Indikation, der Behandlung und der durch dieselbe erzielten Resultate befaßten. Die einzelnen Statistiken sind dabei so widersprechend und different, daß infolge der Gegensätze ein undeutliches Bild des Heilerfolges zutage tritt, was die Entscheidung, sich für die eine oder andere Seite auszusprechen, schwierig erscheinen lassen könnte.

Bedeutete doch vor 25 Jahren das Ulcus ventriculi geradeso wie das Magencarcinom ein chirurgisches noli me tangere, so lange, bis durch Billroths befruchtenden Gedanken die Chirurgie auch dieses Gebiet sich errang. In jenen Fällen, wo wegen gutartiger Narbenstenose oder wegen perigastritischer Verwachsungen, wegen Ulcus simplex oder wegen callösen penetrierendem Magengeschwür die Gastroenterostomie ausgeführt wurde, ist das so häufige, momentane und eklatante Schwinden jeglicher subjektiven Symptome, mit dem oft plötzlichen Aussetzen des Erbrechens und der Schmerzen dem klinischen Beobachter ein wohlbekanntes Bild geworden und nur eine Frage mußte berücksichtigt werden: ist die erzielte Wirkung eine dauernde, steht sie im Einklang zwischen der Gefahr des Leidens an und für sich, und der Gefahr des Eingriffes, und kann sich die Funktion des Magens, die durch die Erkrankung so verändert war, wieder in normale Formen begeben? Mit anderen Worten, wird der Chemismus der Verdaung, die meist vorhandene Hyperchlorhydrie, die motorische Insuffizienz durch eine Gastroenterostomie behoben und werden nicht durch die Gastroenterostomie neue, das Leben des Patienten bedrohende Gefahren heraufbeschworen?

Die Gefahren der Gastroenterostomie sind - abgesehen von jenen, die jede Laparotomie mit der meist nicht zu vermeidenden Narkose in sich birgt - in erster Linie der Circulus vitiosus, und das peptische postoperative Jejunalgeschwür. Auf beide diese Gefahren und auf die Möglichkeit, sie zu vermeiden, werden wir im folgenden noch zurückkommen.

Znnächst soll berücksichtigt werden, welche Resultate die interne Medikation bei der Behandlung des Ulcus ventriculi erzielte. Auf dem Chirurgenkongreß 1897 hat Leube und mit ihm in teilweiser Übereinstimmung Mikulicz die Resultate beider Lager vorgetragen 
und damals erfolgte auch eine relative Einigung in bezug auf die Indikationsstellung zu chirurgischen Eingriffen. Leubes bekannte Behandlungsmethode mit heißen Kataplasmen, Karlsbader Wässern und geregelten Diätformen bei Bettruhe für die erste Zeit der Behandlung, veranlaßte ihn auf Grund seines Beobachtungsmateriales, folgende Resultate bekanntzugeben. In $3 / 4$ aller Fälle erzielte Leube Heilung, in $1 / 5$ wesentliche Besserung und nur in 4 Proz. aller Beobachtungen war das Resultat ein schlechtes, 2,4 Proz. endeten letal. Mithin käme in 96 Proz. bezw. selbst bei radikalem Vorgehen in 75 Proz. die chirurgische Behandlung gar nicht in Betracht.

Aber auch da ist nach Leubes Ausspruch erst nach wiederholter resultatloser interner Behandlung ein chirurgisches Vorgehen am Platz. Nach Warren ${ }^{1}$ ) kamen auf 125 intern behandelte Ulcera 43 Dauerheilungen, 54 Erfolge mit Recidiven, drei Fälle von Übergang in Carzinome, 13 Fälle von Dilatation und 12 Todesfälle durch Perforation oder Blutung, mithin 43,2 Proz. teilweiser, 34,4 Proz. vollkommener Erfolge. Die Entlassungsstatistik nach Schulz ergibt auf 291 Fälle 165 Heilungen, 95 waren gebessert, 15 ungeheilt, 16 Fälle gestorben. Das würde einem momentanen Erfolg von 89 Proz. entsprechen. Von diesen Fällen jedoch konnte Schulz 157 Patienten nachuntersuchen. Von 97 als geheilt Entlassenen waren nur 84 gesund geblieben. 37 litten an geringen Beschwerden. Von diesen geheilten hatten aber 17 (13 Proz.) Rezidiven überstanden. Es ergibt mithin die ungemein objektiv gehaltene Statistik von Schulz 64 Proz. dauernder Erfolge, 13 Proz. temporärer Mißerfolge und 23 Prozent endgültiger Mißerfolge. ${ }^{2}$ )

Statistische Mitteilungen über intern behandelte Kranken sollten mit chirurgischen Statistiken nicht verglichen werden, denn wir dürfen nicht außer acht lassen, daß die meisten Fälle des Operateurs trotz wiederholter interner Behandlung ungeheilt geblieben sind. Mit diesem vielfach noch geschwächten und herabgekommenen Material hat es der Chirurg zu tun. Und noch eines mag in bezug auf unsere im folgenden ausgeführten Resultate in Betracht kommen,

1) Warren, zitiert nach Krönlein, Langenbecks Archiv, Bd. 79.

2) Es ergibt sich daraus, daß die günstigen Heilerfolge der internen Therapie doch oft nur vorübergehend und als unmittelbare Grundlage für die Beurteilung des Erfolges gleich nach der Entlassung uubrauchbar sind. Erst die weitere Beobachtung der Fälle, eine Nachuntersuchung oder wenigstens das Einholen brieflicher Mitteilungen nach mindestens 6 Monaten lassen eine Entscheidung über den Wert einer Behandlung zu. 
Zur Statistik der Gastroenterostomien bei benignen Magenerkrankungen. 501

daß es bei klinischem und nicht der Privatpraxis entnommenem Material sich um Personen handelt, die unmittelbar nach der Entlassung sich nicht schonen können, sofort wieder ihrem oft schweren Beruf nachgehen müssen, sich schlecht und nicht ausgiebig, oder in einer Weise nähren, die einem nicht nur durch lange Krankheit, sondern auch durch einen operativen Eingriff tangierten Magendarmtrakt eine schwere Verdauungsarbeit zumutet.

Um nochmals auf Leubes Statistik vom Jahre 1897 zurïckzukommen, möchte ich die Worte Krönleins zitieren (1906): „Läge in diesen Zahlen (Leubes) der wirkliche und richtige Ausdruck für die Leistungsfähigkeit der internen Therapie beim Magengeschwür, so müßten wir gestehen, daß dieses Leiden doch im ganzen einen ziemlich harmlosen Charakter besitzt, eine zweckmäßige und konsequent durchgeführte Behandlung vorausgesestzt, und daß jedenfalls der Chirurg nur in ganz seltenen Fällen in die Lage kommen kann, sich mit dem Magengeschwür therapeutisch zu beschäftigen, es sei denn, daß er sich dem schweren Vorwurf aussetzen wolle, lebensgefährliche Operationen überflüssigerweise auszuführen." Mit Leubes Indikationsstellung wäre das chirurgische Handeln ein sehr beschränktes, die Operation, die als Radikalbehandlung zu betrachten ist, wäre auf die Stufe eines ultimum refugium herabgedruickt. Heute wird der Kreis der Indikationsstellung weiter gezogen.

Nach Gerhardt ${ }^{1}$ ) sterben 3-5 Proz. der nicht operierten Ulcusfälle an Verblutung, 13 Proz. erliegen einer Perforation, 10 Proz. gehen an den Folgen der Pylorusstenose zugrunde, während Halbersohn ${ }^{2}$ ) bei 120 Ulcusfällen 18 Proz. durch Perforation des Geschwüres und 14 Fälle durch Blutung als letal geendet verzeichnet. Diese Statistiken lassen ein chirurgisches Handeln wohl begründet erscheinen. Welseh verzeichnet 6,5 Proz. Todesfälle durch Perforation und an Verblutung sterben nach Mikulicz und nach Debove und Rémond-5.Proz. Vergleichen wir diese Statistiken untereinander, so ist ein Widerspruch der Angaben Leubes mit den anderen Mitteilungen unverkennbar.

Die Resultate der inneren Therapie des Ulcus ventriculi scheinen nur dann sehr günstig zu sein, wenn es sich um sehr leichte Fälle handelt, die sogar unter Umständen gar nicht zum Arzte kommen, kaum einen Chirurgen aufsuchen. Und wie viele dieser als geheilt bezeichneten Kranken sind auch wirklich geheilt? In solchen Fällen,

1) Gerhardt, Deutsche med. Wochenschr. 1888, zitiert nach Mikulicz Grenzgebiete der Chir. u. Med. 1897.

2) Halbersobn, zitiert ibid. 
die leichte Symptome, keine schweren Ernährungsstörungen zeigen, mag die interne Therapie am Platze sein, entweder im Sinne Leubes oder im Sinne der von Fleiner propagierten Therapie mit Opiaten und Wismuth, die trotz des Widerspruchs Nothnagels zahlreiche Verfechter gefunden hat (Pick, Crämer, Bouveret), um so mehr als sie durch die Versuche Mathes eine experimentelle Stütze gefunden zu haben scheint. Welche interne Therapie einzuschlagen sei, ist hier selbstverständlich nicht zu entscheiden, auch gar nicht Zweck dieser Zeilen.

Jedenfalls - darüber ist wohl völlige Einigkeit vorhanden kann man es bei einem offenen Magengeschwür, bei dem weder die Symptome des Pyloruskrampfes, noch Blatungen, noch Zeichen schwerer Inanition im Vordergrunde des Krankheitsbildes stehen, mit einer rationell geleiteten, gewissenhaften internen Therapie versuchen, das Ulcus zur Ausheilung zu bringen. Hören die Beschwerden trotz strenger diätetischer Behandlung nicht auf, kehren sie kurz nach Beendigung einer Ulcuskur wieder und bringen sie den Patienten langsam körperlich und psychisch herunter, dann ist auch bei Fehlen von Stenoseerscheinungen chirurgisches Handeln am Platze. Dem Ulcus folgt konsekutiv ein Pyloruskrampf, diesem eine Stagnation des Mageninhalts, gefolgt von vermehrter Salzsäureproduktion und dieser wiederum eine Reizung des Geschwürbodens in erhöhtem Grade. ${ }^{\text {) }}$ (Talma Doyen). Wieweit eine allzu konsequente Durchführung interner Behandlung führen kann, mag die von Albert veröffentlichte Beschreibung eines, 17 Jahre intern behandelten, durch Gastroenterostomie geheilten Falles illustrieren. ${ }^{2}$ ) Berücksichtigen muß man außerdem die geringe Mortalität operativer Eingriffe, die geringer sein dürfte als die Mortalität interner Therapie. "Die Lebensgefahr, in welcher sich ein Kranker mit offenem Geschwür befindet, ist zumindest nicht geringer, höchstwahrscheinlich größer, als die Gefahren, welchen wir heute den Kranken durch eine technisch vollendete Operation aussetzen" (Mikulicz). Wenn nun auch zugegeben werden muß, daß ein Ulcus ventriculi unter medizinischer, oft lange dauernder Behandlung ausheilen kann, so geht es doch nicht an, anzunehmen, daß eine stenosierende Narbe mit konsekutiver Gastrektasie, perigastritische Adhäsionen mit Knickung des Pylorus und Dilatation des Magens im Gefolge eines Ulcus ventriculi, oder andere durch entzündliche

1) Le pylore est l'enemie (Doyen).

2) Derselbe befindet sich jetzt, 16 Jahre nach der Operation, noch vollkommen wohl und arbeitsfähig. 
Zur Statistik der Gastroenterostomien bei benignen Magenerkrankungen. $5(13$

Prozesse bedingte Verwachsungen interner Therapie völlig weichen. Eindämmen, einschränken, wird man die motorische Insuffizienz können, ihrem Vorwärtsschreiten, der Entwicklung eines hohen Grades derselben wird man durch interne Mittel begegnen, heilen, ganz beseitigen wird man die Stenose auf internem Wege nie. Wenn die Stenoseerscheinungen, trotzend jeder internen Behandlung, zunehmen, dann bilden sie neben dem komplizierten Magengeschwür. sogar eine absolute Indikation zur operativen Behandlung.

Während nun Salzer aus der II. Chirurgischen Klinik in Wien 1899 für die Zeit vom Jahre $1894 / 95$ bis $1897 / 98$ im ganzen 39 Fälle von Magenoperationen, wovon 20 Gastroenterostomien waren, zusammenstelle, konnte Exner für die nächsten 5 Jahre, bis zum 1. Oktober 1903, 121 Operationen am Magen für seinen Bericht verwerten. Hiervon waren unter Salzers Fällen 6 Gastroenterostomien bei gutartiger Pylorusstenose mit 3 Todesfällen, mithin 50 Proz. Mortalität, während die übrigen drei Geheilten ein sehr gutes Resultatin bezug auf Heilung boten. In den folgenden 5 Jahren wurden an der Klinik 30 Gastroenterostomien wegen gutartiger Stenosen und 3 Exzisionen von Narben und Geschwüren ausgeführt. Die nächsten 3 Jahre brachten ein starkes Ansteigen der chirurgischen Eingriffe, nämlich 76 Fälle von Gastroenterostomien und eine Jejunostomie bei schwerster Blutung (Heilung). Die im Quinquenium 1898-1903 operierten, von Exner veröffentlichten Fälle ergeben 3 postoperative Todesfälle, unsere weiteren 76 Fälle 4 gestorbene, demnach う,26 Proz. Mortalität. Hinzuzuzählen wären noch 3 Explorativlaparotomien bei drei an schwerster Hysterie und Symptomen der Pylorusstenose leidenden Patientinnen, sämtliche mit glänzendem Dauerresultat.

Tabelle I.

\begin{tabular}{r||c|c|c|c}
\hline Zeit und Autor & $\begin{array}{c}\text { Zahl } \\
\text { der Fälle }\end{array}$ & Geheilt & Gestorben & Proz. \\
\hline \hline $1894 / 95-1897 / 98$ (H. Salzer) . . & 6 & 3 & 3 & 50 \\
$1898-1903$ (X) (Exner) . . . . & 30 & 27 & 3 & 10 \\
X 1903-1906 (IX) (diese Arbeit) & 76 & 72 & 4 & 5,26 \\
\hline Summe & 112 & 102 & 10 & 8,92
\end{tabular}

Unsere Statistik in den letzten 12 Jahren ergibt somit 112 Gastroenterostomien bei benignen Magenstenosen mit insgesamt 10 Todesfällen, einer Mortalität von 8,9 Proz. Berücksichtigt man, daß die ersten Fälle einer früheren Zeit angehören, einer Zeitperiode, 
die der, der Pehamschen Statistik zugrunde liegenden entspricht, und zieht man diese Fälle ab, so gestaltet sich die Mortalitätsstatistik wesentlich besser. Peham aus Alberts Klinik berechnete 5(),7 Proz. Mortalität für alle Gastroenterostomien, 41,6 Proz. für die gutartigen Stenosen allein, Mintz beobachtete 71 Proz. operativer Heilungen. Je jünger die Statistiken sind, desto besser gestaltet sich das operative Resultat, dank dem Umstand, daß die Technik in der Hand geübter Operateure immer präziser sich gestaltet.

Zum Vergleiche mögen einzelne Statistiken aus der Literatur herangezogen werden ( $\mathrm{s}$. Tabelle II, S. 505).

Vergleicht man die einzelnen Statistiken miteinander, so kann man ein Absinken der Sterblichkeitsziffer in den letzten Jahren konstatieren. Dies mag in der immer präziser arbeitenden Technik und in der Verkürzung der Operationsdauer seinen Grund haben, zum Teil vielleicht auch darin, daß gerade Pneumonien in der Mortalität der Gastroenterostomien einen hervorragenden Platz einnehmen und durch die in den letzten 10 Jahren allgemein eingeführte trockene Asepsis leichter vermieden werden können. Die Sterblichkeitsziffer nähert sich in den letzten Mitteilungen einer recht niedrigen Zahl und wird voraussichtlich noch allmählich herabgedrückt werden.

Um nun auf die Ursache der Erkrankung einzugehen, so muß man wohl zugeben, daß die Ätiologie des Ulcus ventriculi und dementsprechend auch seines Folgezustands eine bis zu einem gewissen Grade noch unklare ist. Verletzungen und künstlich gesetzte Defekte der Magenschleimhaut heilen ohne weiteres glatt in einigen Tagen aus und nur durch Verätzung des Bodens des Defektes konnte Fibich ein torpides, jeglicher Heilungstendenz entbehrendes Geschwür der Magenschleimhaut erzeugen. Ob wirklich autochthone embolische Prozesse eine Ursache spielen, läßt sich nicht entscheiden, jedenfalls ist die Theorie (Pavy) der selbstverdauenden Wirkung des Magensaftes eine nach den neuesten Untersuchungen nicht mehr geltende Behauptung. Es muß jedenfalls ein Absterben eines gewissen Schleimhautbezirks eintreten, bevor die Wirkung des Magensaftes in Frage kommt, und dies kommt nicht nur für das Magengeschwür, sondern auch für das peptische Jejunalgeschwür in Frage. Die Ätiologie der Magenstenose benigner Natur ist bei der Ausdehnung dieses Begriffs eine sehr verschiedene.

Abgesehen von der seltenen angeborenen Pylorusstenose (A bel, Neurath [35 Fälle], Trantenroth [12 Fälle]) bietet bisweilen ein 
Zur Statistik der Gastroenterostomien bei benignen Magenerkrankungen. 505

Tabelle II.

\begin{tabular}{|c|c|c|c|}
\hline Autor & $\begin{array}{c}\text { Zahl der Fälle } \\
\text { (Gastroenterostomie) } \\
\text { benigne Erkrankungen }\end{array}$ & $\begin{array}{c}\text { Ge- } \\
\text { storben }\end{array}$ & Proz. \\
\hline Haberkant & 50 & 10 & 20 \\
\hline Mindler & - & - & 11,1 \\
\hline Chlumsky & 23 & 1 & 4,35 \\
\hline Trendel & - & - & 18,2 \\
\hline Chlumsky & $\left\{\begin{array}{l}1881-1885=28,5 \text { Proz. } \\
1886-1890=35,7 ", \\
1891-1896=10,86 ",\end{array}\right\}$ & - & 21,42 \\
\hline Robsohn & - & - & 16,4 \\
\hline Körte & - & -- & 20,6 \\
\hline Schloffer & 15 & 4 & 26,6 \\
\hline Krogius & - & $\ldots$ & 31 \\
\hline Clairmont & 33 & 8 & 24,2 \\
\hline Clairmont $\left\{\begin{array}{l}\text { v. Hacker } \\
\text { Wölfler }\end{array}\right.$ & $\begin{array}{l}23 \\
10\end{array}$ & $\begin{array}{l}5 \\
3\end{array}$ & $\begin{array}{c}21,8 \\
30\end{array}$ \\
\hline $\begin{array}{c}\text { Eiselsberg } \\
1906\end{array}\left\{\begin{array}{l}\text { Ulcus blutend } \\
\text { Ulcus ohne Blutung } \\
\text { Narbenstenose }\end{array}\right.$ & $\begin{array}{l}15 \\
20 \\
39\end{array}$ & $\begin{array}{l}3 \\
3 \\
1\end{array}$ & $\begin{array}{l}20 \\
15 \\
2,5\end{array}$ \\
\hline Krönlein 1906 & 89 & 10 & 11,2 \\
\hline Kreuzer 1906 & - & -- & 7,6 \\
\hline Clairmont 1906 & 91 & 10 & 11 \\
\hline Delaloye 1906 & 38 & 6 & 15,7 \\
\hline (v. Hacker & 22 & 5 & 22,7 \\
\hline $\begin{array}{l}\text { Hofmann } \\
1906\end{array}\left\{\begin{array}{l}\text { v. Hacker } \\
+ \text { Knopf } \\
\text { Billroth-Brenner }\end{array}\right\}$ & $\begin{array}{r}15 \\
2\end{array}$ & $\begin{array}{l}1 \\
2\end{array}$ & $\begin{array}{r}6,6 \\
100\end{array}$ \\
\hline Kramer 1906 & 100 & 10 & 10 \\
\hline Mayo Robsohn & - & - & 3,7 \\
\hline Unsere Gesamtstatistik & 112 & 10 & 8,92 \\
\hline $\begin{array}{l}\text { Letzte Reibe } \\
\quad(\mathrm{X}, 1903-1906, \mathrm{IX})\end{array}$ & $72\left\{\begin{array}{l}\text { Gussenbauer } 8\} \\
\text { Hochenegg } 64\end{array}\right\}$ & 4 & 5,26 \\
\hline $\begin{array}{l}\text { Privatpraxis Prof. Hocheneggs } \\
\text { seit dem Jahre } 1890\end{array}$ & 26 & 2 & 7,7 \\
\hline $\begin{array}{l}\text { Unsere Gesamtstatistik inkl.der } \\
\text { privaten Fälle Prof.Hocheneggs }\end{array}$ & 138 & 12 & 8,4 \\
\hline
\end{tabular}


Trauma, entweder ein einmaliges oder ein wiederholt auftretendes, das ätiologische Moment für die Entstehung eines Magengeschwürs. Wenn man die Beobachtung Hofmanns berücksichtigt, der bei einem zwischen Wagenpuffer eingequetschten Mann eine handtellergroße Abhebung der Magenschleimhaut fand, den Fall Roses (Zerreißung des Magens durch Verschütten) in Betracht zieht, so muß es begreiflich erscheinen, daß durch Einwirkung einer vielleicht nicht sehr großen Gewalt in die Magengegend es zu leichten oder schweren Schleimhautläsionen kommt, auf Grund derer es dann, besonders wenn die das verletzte Gebiet versorgenden Blutgefäße gequetscht oder durch Thrombenbildung verschlossen sind, zur Geschwürbildung kommt. Übrigens erzielte Ritter ${ }^{1}$ ) durch Schläge gegen den Magen im Experiment ausgedehnte hämorrhagische Ergüsse der Schleimhaut; nach Hauser ${ }^{2}$ ) können primäre hämorrhagische Infarkte zu Geschwürsbildung führen, ebenso wie durch embolische oder spontan thrombotische Prozesse der Magenschleimhaut. Die alarmierenden Symptome nach einem Trauma, der Chok und die oft nicht unbedeutende Blutung können in kurzer Zeit vergehen, der Patient erholt sich vollständig und erst viel später, vielleicht erst nach Jahren, kommt es zum Ausbruch neuer deutlicher Symptome.

In der Literatur sind zahlreiche Fälle mitgeteilt; einige sollen hier erwähnt werden. Krönlein-(Leube) beschreibt einen Fall, wo durch StoB gegen einen Sattelknopf ein Ulcus sich bildete, einen anderen Fall beschreiben Körte und Herzfeld, Stoß gegen eine Brettkante. Brenners Patient fiel auf den Rucken, litt dann jahrelang an Magenbeschwerden und pechschwarzen Stühlen, bei der Operation fand man ein callöses Ulcus. Steinthals Patient fiel glatt auf den Bauch, bald darauf bekam er Hämatemesis. Winiwarters Fall war ein StoB gegen den Bauch beim FuBballspiel. Riedel fand Adhäsionsbildung nach Trauma, Körte ein Geschwür. Kreuzer hat in seiner jüngst erschienenen Arbeit 4 Fälle zusammengestellt, von denen zwei bereits 1899 von Krönlein publiziert worden waren. Einmal war es ein heftiger Sto $B$ mit einer Heugabel, einmal ein Fall auf einen Sattelknopf, einmal Überfahrenwerden, einmal wiederholte Druckwirkung auf das Abdomen bei einer Büglerin. $\mathrm{Za}$ den chronischen Traumen kann man die Disposition der Spiegel- und Metallschleifer (Bouveret) und der Porzellanschleifer (Bernitz) rechnen (Lieblein-Hilgenreiner).

Unter unseren Fällen sind es 5, in denen anamnestisch Trauma als Ursache der Magenerkrankung angegeben wird. Dazu kommt ein weiterer, nicht operierter Fall (Fall 13, 24, 29, 30, 39),

1) Zitiert nach Mathes.

2) Zitiert nach Pagenstecher. 
Zur Statistik der Gastroenterostomien bei benignen Magenerkrankungen. 507

Fall 13. Schlag der Kurbel eines rotierenden Rades gegen den Magen, heftige Schmerzen durch 24 Stunden, ein halbes Jahr später typische Ulcusbeschwerden.

Fall 24. Vor 7 Monaten fiel dem Pat. eine schwere Eisenplatte auf den Bauch. Lange Zeit Schmerzen, später Brechreiz, Abmagerung, Ulcussymptome.

Fall 29. Vor 20 Jahren durch einen Wagen überfahren worden.

Fall 30. Pat. ist Stockbieger. Bei seinem Beruf prebt er immer ein Ende des zu biegenden Stockes gegen den Magen. Seit langer Zeit (31 Jahre) Magenbeschwerden.

Fall 39. Pat. wurde durch einen rollenden Baumstamm in die Magengegend getroffen. Einige Tage später Magenbeschwerden und Erbrechen, andawernd.

Nicht operierter Fall. Pat. bekommt einen heftigen Stoß gegen die Magengegend. Nach einer Stunde Brechreiz, am anderen Tag blutige Stühle. Konstante Magenbeschwerden. Nach 3/4 Jahr Hămatemesis.

Es läßt sich, wie schon erwähnt, die Entstehung eines Ulcus ventriculi durch ein Trauma leicht erklären, vielleicht kommt dies sogar offer zustande und es scheinen chronisch einwirkende wiederholte 'Traumen, wenn auch geringen Grades, zu genügen, um Adhäsionen hervorzurufen. Im Moment des Traumas bestehende oder kurz vorher bestandene abnorme Sekretionsverhältnisse dürften dies noch begünstigen. „Es ist vollkommen einwandfrei erwiesen, daß durch Kontusionen des Abdomens Verletzungen entstehen können, welche in relativ kurzer Zeit zu Narbenstriktur und Geschwürsbildung führen" (Krönlein).

$\mathrm{Zu}$ den Traumen im weiteren Sinne gehören Verätzungen.

Mindler erwähnt Verätzungen mit Schwefelsäure, Klemperer Salzsäure, Czerny-Rindfle isch mit Kalilauge, Carle und Fantino, v. Eiselsberg mit Säuren. In jeder Statistik sind derartige Fälle erwähnt, wir selbst beobachteten $z$ wei Fälle, in denen Stenoseerscheinungen nach Verätzungen eintraten (Fall 5 Kalilauge, Fall 17 Lysol).

Stenosen auf Grund dyskrasischer Prozesse, von denen Titow, Payr D'Ursi luetische Stenosen, Dombrowsky einen Fall von Kompression durch tuberkulöse Drüsen, Petersen $u$. Machol, Fischer rein tuberkulöse Prozesse des Magens beschrieben, haben wir nicht beobachtet. Ein Fall starb allerdings später an multiplen Stenosen des Dünndarmes, tuberkulöser Natur, doch konnte weder bei der Operation noch bei der Sektion eine tuberkulöse Erkrankung des Pylorus diagnostiziert werden (Fall 40).

In den anderen Fällen bleibt die Ätiologie ziemlich unklar. Mögen es primäre Erkrankungen der Magengefäße sein (Virchow) oder autochthone Thrombosen und Embolien oder primäre Veränderungen der sekretorischen Tätigkeit. In vielen Fällen sind es 
perigastritische Prozesse in der Umgebung des Pylorus, Peripyloritis, Cholelithiasis und Pericholecystitis, Verwachsungen nach Peritonitiden oder Knickungen durch Verziehnng der veränderten Leber (Cirrhose).

Im allgemeinen wird, besonders von den Internisten, hervorgehoben, daß das weibliche Geschlecht an gutartigen Magenaffektionen mehr leide als das männliche. Leube gibt an, doppelt soviel Frauen als Männer beobachtet zu haben. Vonwyl legt sogar dem häufigen Vorkommen des Magenulcus bei Frauen und dem häufigeren Vorkommen des Duodenalgeschwürs bei Männern einen differentialdiagnostischen Wert bei. Welch (zitiert nach Kaupe) gibt bei 1700 Ulcuskranken das Verhältnis mit 60 Proz. W. und 40 Proz. M. an. Auch Franke, Körte und Herzfeld haben mehr Frauen als Männer unter ihren Ulcuskranken. Brinton ${ }^{1)}$ fand unter 664 Kranken $440 \mathrm{~W}$. Rokitansky ${ }^{1}$ ) unter 76 Fällen $46 \mathrm{~W}$., Habersohn unter 201 Patienten 127 W. ${ }^{1}$ )

In den chirurgischen Statistiken sind die Verhältnisse etwas anders. Hier überwiegen oft die Männer oder sind an Zahl gleich den Frauen. Männer an Ulcus ventriculi erkrankt, sind meist mehr in ihrem Berufe behindert als die Frauen und empfinden das Leiden dementsprechend viel härter, ihre Lebensweise ist oft eine unregelmäßige, dadurch steigern sich noch die Symptome und so kommt es, daß Männer eher sich veranlaßt fühlen, den Chirurgen aufzusuchen als Frauen, unter denen nur die schweren Erkrankungen zur Operation gelangen. Hofmann aus Hackers Klinik brachte einen Bericht über 52 Fälle, darunter $24 \mathrm{~W}$. und $28 \mathrm{M}$. Unter unseren Patienten sind $41 \mathrm{M}$. und $35 \mathrm{~W}$. In bezug auf das Alter betrachtet fallen die meisten Erkrankungen in die 4 Dekade. Das Alter unserer Kranken ist im nachfolgenden veranschaulicht.

Tabelle III.

\begin{tabular}{l|c|c|c|c|c|c|c||c}
\hline \hline \multicolumn{1}{c|}{ Alter } & $1-10$ & $10-20$ & $20-30$ & $30-40$ & $40-50$ & $50-60$ & über 60 & Summe \\
\hline \hline Männer & - & - & 8 & 18 & 9 & 5 & 1 & 41 \\
Frauen & - & 4 & 13 & 9 & 5 & 4 & - & 35 \\
\hline
\end{tabular}

Die meisten Kranken standen also übereinstimmend mit Brintons Angaben zwischen dem 30. und 40. Lebensjahre; die jüngste Patientin war 12, der älteste Kranke 61 Jahre alt.

1) Sämtliche zitiert nach Lieblein und Hilgenreiner. 
Zur Statistik der Gastroenterostomien bei benignen Magenerkrankungen. 509

Die Daller des Leidens vom Beginne der ersten Symptome bis zur Operation betrug in 13 Fällen weniger als ein Jahr, in 35 Fällen mehr als ein und weniger als 5 Jahre, 10 mal mehr als 5 und weniger als 10 Jahre, je 5 mal mehr als 10 und weniger als 15 bezw. 15-20 Jahre, in 7 Fällen erstreckte sich die Krankheitsdauer über mehr als 20, 1 mal über mehr als 30 Jahre.

Unter den subjektiven Symptomen nimmt der lokale Schmerz die erste Stelle ein. Als klopfender quälender Schmerz empfunden, wird er oft durch Nahrungszufuhr ausgelöst, besonders heftig in gewissen Seitenlagen empfunden und wird wohl durch die chemische und mechanische Reizung des Geschwürsbodens hervorgerufen. Er findet sich in 90 Proz. unserer Fälle verzeichnet.

Weniger oft findet sich ein Druckpunkt. Er ist bald genau in der Mittellinie oberhalb des Nabels lokalisiert, bald findet er sich auch links von derselben, besonders dann, wenn es sich um entzündliche Tumorbildung handelt. Nach Mendel und Reiter $\left.{ }^{1}\right)$ läßt er sich perkutorisch sicher lokalisieren und kommt sowohl bei Geschwüren der vorderen als auch der hinteren Magenwand vor, er findet sich in unserer Beobachtungsreihe in 50 Proz. der Fälle angegeben.

Das Erbrechen tritt meist nach Nahrungsaufnahme, selten unabhängig von derselben auf, oft erst mehrere qualvolle Stunden nach der Einnahme einer Mahlzeit. Es schafft fast immer Erleichterung von den starken Schmerzen und wird daher bisweilen seitens der Patienten absichtlich provoziert. 81) Proz. unserer Fälle litten daran.

Blutungen aus dem Magen, teils frisch, teils halbverdant als Melaena sind unter unseren Fällen $27 \mathrm{mal}$, blutige Stühle sind $6 \mathrm{mal}$, charakteristische pechschwarze Stühle 20 mal angegeben.

Obwohl die Aciditätswerte beim Ulcus ventriculi nicht nur nicht vermehrt sein müssen, ja sogar Anacidität bestehen kann, so ist doch das Vorhandensein freier HCl im Magensaft, bei fehlender Milchsäure ein sehr charakteristisches Symptom, Milchsäure allein ist sicher ein höchst verdächtiges auf Carcinom hinweisendes Vorkommnis. In 51 Fällen vor der Operation ausgeführt, ergab die chemische Untersuchung $46 \mathrm{mal}$ freie $\mathrm{HCl}$ bei fehlender Milchsäure, 1 mal war sowohl $\mathrm{HCl}$ als auch Milchsäure, 3 mal war weder $\mathrm{HCl}$ noch Michsäure vorhanden, 2 mal war die Untersuchung auf Milch-

1) Lieblein-Hilgenreiner. 
säure positiv bei negativem Befunde für $\mathrm{HCl}$. Diese beiden Fälle starben später an Carcinom.

Magenerweiterung. Kaiser unterscheidet 3 Grade von Magendilatation, solche, wo die große Kurvatur in der Nabelhorizontalen liegt (1. Grad), wo sie bis zur Mitte zwischen Symphyse und Nabel reicht (2. Grad) und solche, wo sie darüber hinausreicht. In 57 Fällen finden wir darüber Angaben. 4 Fälle boten eine Erweiterung 3. Grades, 14 eine solche mittleren Grades, die übrigen zeigten keine besonders große Gastrektasie. Tumoren oder eine fühlbare, oft undeutliche Resistenz wurden in 9 Fällen der untersuchten Kranken gefunden.

Magenplätschern. Nach Küttner hat es nur eine Bedeutung, wenn es bei nüchternem Magen gefunden wird, allein auch dann, wenn bei stoßweiser Palpation außerhalb des Bereiches normaler Magengrenzen selbst bei gefülltem Magen Plätschergeräusche nachgewiesen werden, verdienen sie eine Beachtung für den Nachweis motorischer Insuffizienz. K. M. Ssapeshko mißt diesem Nachweis eine ziemliche Bedeutung bei. Bei nüchternem Magen untersucht, wurde bei unseren Kranken Magenplätschern 37 mal nachgewiesen. Dabei gelingt es bisweilen, stärkere peristaltische Bewegungen zu provozieren, die dann bei bestehender Stenose das deutliche, charakteristische Bild der "Magensteifung" geben. Letztere wurde 8 mal beobachtet.

Die einzelnen Fälle unserer Beobachtungsreihe verteilen sich auf die den Eingriff indizierenden Erkrankungen folgendermaßen:

I. Narbenstenose und Ulcus am Pylorus. Einen wesentlichen Unterschied zwischen einer Narbenstenose und einem dem Pylorus stenosierenden Ulcus kann man, selbst bei der Operation, wohl nur in den seltensten Fällen machen. Denn ob ein den Pylorus stenosierendes Geschwür, bereits vollständig geheilt, nur als Narbe Erscheinungen hervorruft, oder ob doch noch an der Narbe Geschwürsprozesse vorliegen, kann man bei der einfachen Inspektion und Palpation während der Operation oft nicht entscheiden. Dazu kommt, daß in den Krankengeschichten die scharfe 'Trennung zwischen Narbe und Ulcus vielfach nicht genügend zum Ausdruck gebracht ist, oft auch, wie erwähnt, nicht ausgesprochen werden kann. Das klinische Bild, das die Fälle von Ulcus und Stenose nach Ulcus bieten, ist zudem meist ein gleiches. Es ist daher gerechtfertigt, wie es auch Hofmann aus v. Hackers Klinik neulich tat, Fälle von floridem offenen Ulcus und von Stenosen narbiger Natur gemeinsam in eine Gruppe zusammenzufassen, um so mehr, als beide Erkrankungs- 
Zur Statistik der Gastroenterostomien bei benignen Magenerkrankungen. 511

formen nur verschiedene Stadien eines und desselben Prozesses darstellen.

An unserer Klinik wurden in den letzten 3 Jahren 47 Fälle von Ulcus ventriculi und Narbenstenose operiert, hiervon entfallen 23 auf das männliche, 24 auf das weibliche Geschlecht. Letal endete nur ein Fall (26), die übrigen wurden geheilt entlassen. Für die Bestimmung des Danerresultats kommen hiervon nur 32 vor dem I. 1906 operierte Fälle in Betracht. 20 von diesen sind als dauernd geheilt zu betrachten, 7 sind wesentlich gebessert, ein Fall ist nachträglich gestorben (Fall 40), 2 blieben verschollen und bei zweien ist das endliche Resultat als ein ungünstiges zu bezeichnen.

Einer dieser Fälle (Nr. 40) wird, da er nachträglich mit multiplen Dünndarmstenosen kombiniert, nochmals zur Operation gelangte, besonders $\mathrm{zu}$ besprechen sein.

II. Fälle von callösem Ulcus: Die zuerst von Hofmeister, später von Brenner beschriebenen callösen Magengeschwüre bilden ein eigenes, vom einfachen Ulcus abzutrennendes Krankheitsbild. Diese penetrierenden Geschwüre, die auf die Leber, Milz, Pankreas, vordere Bauchwand, kurz auf die Nachbarorgane hinüberzugreifen die Tendenz besitzen, durch Infektion und Perforation zn subphrenischen Abszessen führen können, scheinen aus dem einfachen callösen, nicht penetrierenden Magengeschwür hervorzugehen. Beide sind wohl nur verschieden weit vorgeschrittene Stadien eines und desselben Prozesses. Brenner, Jedlicka, Cačkovič, Schwarz, Krönlein, Mikulicz vertreten, oft in energischer Weise, die Ansicht, daß beim callösen penetrierenden Magengeschwür und auch beim nicht penetrierenden die Exzision, beziehungsweise die Resektion des Geschwürs das richtige, ja das einzig richtige Vorgehen darstelle, "wie viele Carcinome, wie viele Perforationen verschuldet die Furcht der Konservativen vor Radikalität", sagt Bakeš. Und doch, ein Verfechter der radikalen Operation bei callösem Ulcus, Brenner, der ebenso wie Jedlička und auf diesen gestützt, die Möglichkeit einer Heilung durch eine Gastroenterostomie negierte, kam doch später durch eigene Beobachtung dazu, die Heilung des callösen Geschwürs durch eine Gastroenterostomie sicher zu stellen. Gezwungen, drei Fälle, die wegen callösen Ulcus gastroenterostomiert worden waren, zu relaparotomieren (wegen Incarceratio interna, Bauchwandhernie und Verwachsungen) konnte er jedesmal konstatieren, daß das derbe callöse Infilfrat geschwunden war. Dies mag dazu dienen, dem Vorwurf, eine Gastroenterostomie bei callösem Magengeschwür sei eine Verlegenheitsoperation, zu begegnen. Auf 
die Möglichkeit hin, ein callöses Ulcus könnte sich zu einem Carcinom entwickeln, zu resezieren, scheint nicht indiziert zu sein, in Anbetracht des Umstandes, daß eine Resektion, wie zahlreiche Fälle beweisen, auch nicht vor Rezidiven schützt und einen wesentlich schwierigeren Eingriff darstellt. Der nicht zu leugnenden Tatsache, daß sich auf Grund eines callösen Ulcus oft ein Carcinom entwickelt, ist dadurch begegnet, daß das Ulcus nach einer Gastroenterostomie der Heilung entgegengeht. Die starken Verwachsungen, die ein callöses Ulcus umgeben, machen die Mobilmachung des Magens sehr schwierig. Beim Versuche, das Geschwür zu mobilisieren, kann es nun zum Einreißen des Ulcus kommen „zu einer Perforation während der Operation, und gerade dieses Einreißen war in den ersten beschriebenen Fällen die Veranlassung zur Resektion, einfach deshalb, weil man nur auf diese Weise das Leben des Patienten retten zu können glaubte" (Lorenz $\left.{ }^{1}\right)$ ). Erfolgt ein derartiges Einreißen, so kann man das von Hochenegg (Lorenz ${ }^{2}$ )) ausgeführte Drainageverfahren anwenden, oder man kann den Defekt durch Organe der Umgebung decken, durch Netzzipfel (Braun, Benett) oder Colon und Netz (Landerer und Glü cksmann) decken; jedenfalls aber muß man die Gastroenterostomie hinzufügen. Dieselbe allein ausgeführt, ist weniger gefährlich und von analogem Erfolg begleitet. Auf der einen Seite ist es die Gefahr der carcinösen Entartung, die Gefahr einer späteren nenerdings auftretenden Blutung, die Möglichkeit einer postoperativen Perforation, die gegen die Gastroenterostomie ins Treffen geführt. Blutungen und Perforationen sind von Ali Krogius, Krönlein, Lieblein, Küster u. a. beschrieben worden. Auf der anderen Seite muß man in Betracht ziehen, daß auch nach Resektion des Ulcus Rezidive, Blutungen aus neuentstandenen Ulceris und Perforationen derselben nicht gerade zu den Seltenheiten gehören (v. Eiselsberg, Hinterstoisser, Brenner, Stich).

Mit der Exzision oder Resektion des Geschwürs wird der kausalen Indikation wohl Genüge geleistet, wenn man aber in Betracht zieht, daß der Gastroenterostomie eine nicht abzusprechende prophylaktische Bedeutung zukommt, so müßte man, wenn gerade auf die Beseitigung des Ulcus ein so großes Gewicht gelegt wird, Resektion mit Gastroenterostomie kombinieren. Da aber zweifellos der Gastroenterostomie anch eine heilende Wirkung zukommt, so

1) Lorenz, Wiener klin. Wochenschr. S. 316 .

2) Lorenz, Wiener klin. Wochenschr. 1903. Nr. 41. 
Zur Statistik der Gastroenterostonien bei benignen Magenerkrankungen. 513

kann und wird sie auch bei ihrer gegenüber der Resektion unverhältnismäßig geringeren Gefährlichkeit als therapeutischer Faktor genügen.

Zum callösen Ulcus im weiteren Sime, nicht als penetrierendes Geschwüx allein können wir 10 Fälle unserer Beobachtung zählen (Fall 6, 12, 13, 21, 23, 28, 39, 53, 56 und 9 der II. Reihe). 7 hiervon betrafen Männer, 3 Weiber. In zwei Fällen war das Geschwür fest mit der Leber verwachsen (6, 13), 3 mal war der Pankreaskopf ergriffen (21, 23, 39), 5 mal war das callöse Geschwür durch perigastritische Adhäsionen (12, 28, 53, 56, 9/II.) an das Colon und die Leber gelötet. Ein Fall endete letal (39). 8 Fälle kommen für die Nachuntersuchung in Betracht, 7 sind als dauernd geheilt, einer als gebessert zu betrachten.

Hierzu zu rechnen wären noch die zwei privat von Hochenegg mit Drainageverfahren behandelten Fälle, die danernd geheilt sind.

III. Unklare auf Carcinom verdächtige Fälle. In zwei der beobachteten Fälle konnte man bei der Operation allerdings nicht ganz den Verdacht zurückweisen, daß es sich doch um ein Carcinom handeln könnte, beidemal wurde trotzdem von einer Resektion Abstand genommen, das eine Mal, da das Individuum zu schwach zu sein schien, um einen derartigen Eingriff zu überstehen, das andere Mal wegen zu starker Adhäsionen. Beide Patienten wurden in gutem Ernährungszustand entlassen. In dem einen Fall, der ca. 8 Monate nach der Operation starb, konnte nur eruiert werden, daß der Patient an einem Magenleiden starb, im anderen Fall, der 11 Monate nach der Operation verschied, wurde bei der Autopsie ein auf Grund einer Ulcusnarbe entstandenes Carcinom sichergestellt.

"Trotzdem es sich hier um Carcinom handelt, muß man doch diese aus Geschwüren und Narben entstehenden Krebse, obwohl sie die Statistik verschlechtern, mitzählen, wenn unsere Zahlen praktische Bedeutung haben sollen." -

IV. Adhäsionen: Adhäsionen nach Perigastritis, Pericholecystitis und Cholecystektomie, ausgedehnte Verwachsungen nach vorher wegen Narbenstenose ausgefïhrter Gastrolysis und Pyloroplastik und Verwachsungen bei bestehender Cholelithiasis boten 15 mal den Anlaß zu einem chirurgischen Eingriff (7 Männer, 8 Frauen). Achtmal waren es einfache Adhäsionen, die, ohne bekannte Ursache entstanden, Beschwerden hervorriefen (16, 19, 38. 45, 3, 8, 19, 20 II. Reihe). Zweimal waren diese Adhäsionen mit 
einer Knickung des Pylorus oder des präpilorischen Anteils kombiniert. Fünfmal waren Verwachsungen mit der steingefüllten Gallenblase oder mit Narben nach Cholecystektomie wegen Cholelithiasis. Im Falle 24 war ein starkes Trauma des Bauches der Erkrankung vorausgegangen, die Verwachsungen gaben dem Magen eine leichte Sanduhrform. Eine Patientin (37) war bereits früher wegen Verwachsungen zweimal operiert worden (Gastrolysis und Pyloroplastik) ohne Erfolg, so daß eine Gastroenterostomie notwendig wurde. Zur Nachuntersuchung kommen 10 Fälle in Betracht, 5 von diesen Patienten sind dauernd gesund geblieben, 4 sind gebessert, in einem Falle blieb der Erfolg aus. Im Falle 37 traten zwar die Symptome seitens des Magens zurück, dagegen bildeten sich Beschwerden durch Verwachsungen zwischen Bauchwand und Darm, die zu chronischer Darmstenose führten.

V. Ulcus duodeni. In 3 Fällen wurde die Gastroenterostomie bei Ulcus duodeni ausgeführt. - Es konnte die Diagnose nicht mit Sicherheit vor der Operation gestellt werden $(25,27,6 / \mathrm{II})$. Zwei endeten letal durch konfluierende Lobulärpneumonie. Ein Fall wurde geheilt entlassen.

Von den in obiger Statistik angeführten 76 Fällen sind jedoch zur Bestimmung der Dauerresultate nur 56 Fälle verwendbar, da die übrigen eine zu kurze Beobachtungsdauer seit der Operation bieten und keine Nachrichten über deren weiteres Befinden vorliegen. Die Krankengeschichten dieser Fälle sind nur kurz in einem Nachtrag besprochen. Es sind das jene Fälle, die in der Zeit rom 1. I. bis 1. X. 1906 zur operativen Behandlung gelangten. Abzüglich dieser 20 Fälle gestalten sich die Operations- und Dauerresultate folgendermaßen (s. Tab. IV, S. 515).

Unter den in Tab. IV angeführten 56 Fällen verloren wir $4 \mathrm{im}$ Anschluß an die Operation. Es sind das zunächst die beiden Fälle von Ulcus duodeni und je ein Fall von Narbenstenose und Ulcus callosum (Fall 25, 26, 27, 39). In 3 Fällen fand man Pneumonie als Todesursache, die Darmnaht war stets suffizient. In Kürze die Obduktionsprotokolle:

Fall 25. Ulcus duodeni. Länglich ovales Ulcus peptic. duodeni der vorderen Wand, Narben nach Ulcus duodeni, Pericholecystitis, Stenose des Pylorus, Magenektasie, chronischer Magenkatarrh, chronische Tuberkulose beider Lungen, totale adhäsive Pleuritis, konfluierende Lobulärpneumonie beider Lungen. Magendarmfistel suffiziert.

Fall 26. Einfaches Ulcus. Kompression und Dilatation des abführenden Gastroenterostomieschenkels bedingt durch Incarceration einer 
Zur Statistik der Gastroenterostomien bei benignen Magenerkrankungen. 515

Tabelle IV.

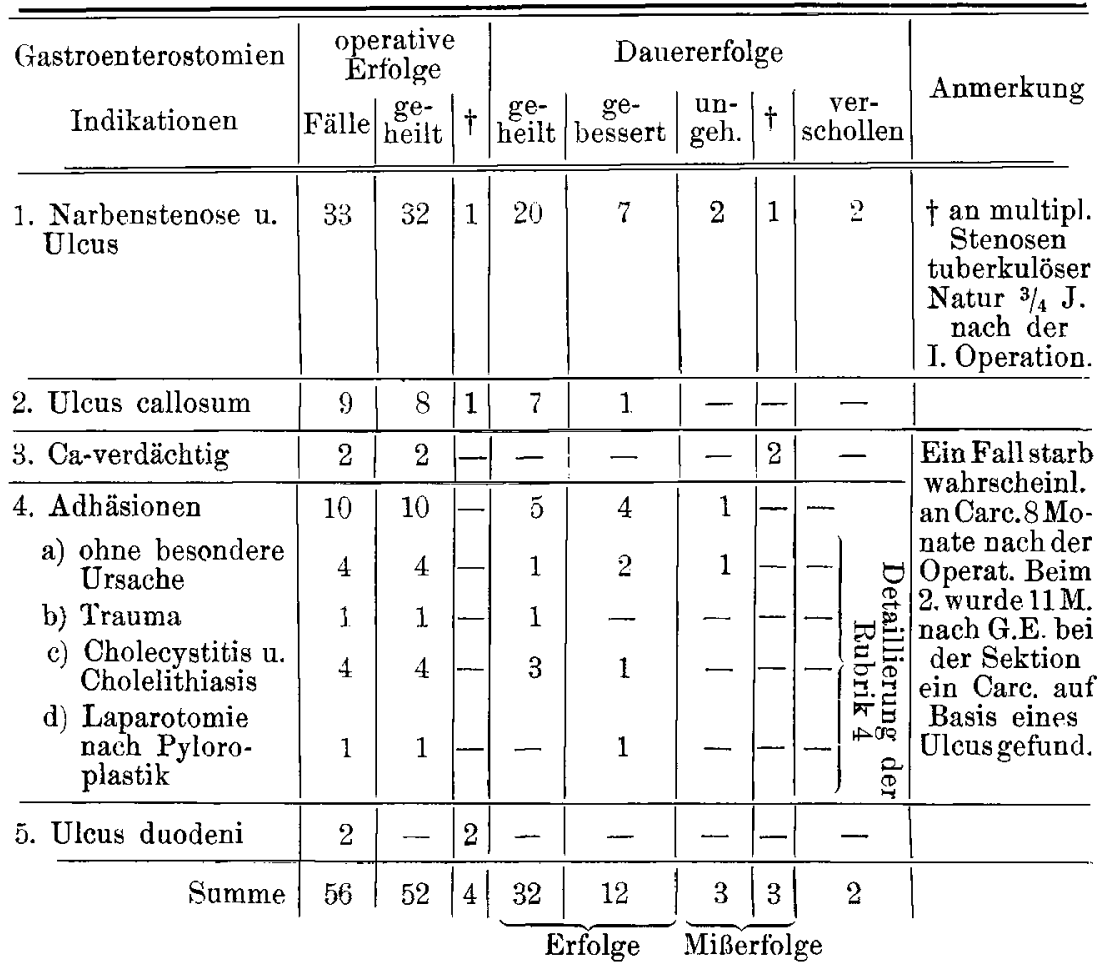

etwa $8 \mathrm{~cm}$ von der Anastomosenöffnung entfernten Dünndarmschlinge in den Mesocolonschlitz. Aspirationspneumonie im Beginn.

Fall 27. Ulcus duodeni: Akutes Lungenödem, eitrige Bronchitis, Magendilatation nach Stenose des Duod. durch eine schrumpfende Ulcusnarbe Stenosis Duct. choledoch. et pancreatic. Enteroanastomose gut funktionierend suffizient.

Fall 39. Ulc. callosum. Großes, callöses, rundes Magengeschwür der hinteren Magenwand, verwachsen mit dem Pankreas. Thrombosis venae portae. Gastroenterostomie gut funktionierend. Lobulärpneumonische Herde beiderseits. Gangränöser Herd rechts, Pleuritis.

Drei dieser Fälle endeten an Komplikation von seiten der Lungen, teils bald nach der Operation, teils erst viel später (20. Tag). Wir können also diese Fälle der Operation als solche nicht zur Last legen, da niemals eine peritoneale Reizung bei der Autopsie gefunden wurde, die Darmnaht sich stets als suffizient erwies. Nur einmal war die Operation bezw. ihr Folgezustand Ursache des letalen Endes. Berücksichtigt muß werden, ob nach der Operation, im Anschluß an die Narkose, Erbrechen eintrat. Dies war 3 mal der Fall. Nach Chlumsky kommt diesem Ereignis eine große Bedeutung zu. Von 24 Gastroenterostomien, die an Pneumonie erkrankten, 
haben - nach Chlumsky - 15, mehr als die Hälfte, erbrochen. Auch Gerulanos spricht von der relativen Häufigkeit von Pneumonien unter Pat., die nach der Operation erbrochen haben. Ob das Erbrechen rein ein postnarkotisches war oder reflektorisch durch Zerrung des Magens und Darmes hervorgerufen wurde, läßt sich nicht entscheiden. Blutiges Erbrechen hat meist seine Ursache darin, daß bei der Operation Blut in den eröffneten Magen gelangt.

Nach Krönleins kürzlich erschienener Arbeit sind für die Begutachtung der Dauerresultate nur Beobachtungen von 6 monatlicher Dauer seit der Operation für die Beurteilung eines Resultates zu brauchen. Einzig allein an ihnen kann man den Wert des erzielten Erfolges beurteilen. Von Krönleins Fällen wurden 60 nachuntersucht, 36 hiervon sind dauernd, das heißt über 6 Monate geheilt, 12 wesentlich gebessert, 6 ungeheilt, 2 gestorben, bei 4 Fällen blieb das Schicksal unbekannt.

Als Kriterium der Heilung möchte ich die subjektiven Symptome in erster Linie gelten lassen. Bleibt bei einem Patienten nach G.-E. durch längere Zeit, mindestens durch ein halbes Jahr, Erbrechen aus, oder tritt es höchstens im Anfang nach der Operation nur ein- oder das anderemal auf, kann der Patient schmerzfrei seinem Berufe nachgehen, und nimmt er, was das Hauptsächlichste ist, wesentlich an Körpergewicht zu, so können wir den Patienten als geheilt betrachten. Die Fehler des Verdauungsmechanismus, Hyperacidität und Hyperchlorhydrie müssen ebenso wie die motorische Insuffizienz geschwunden sein oder zumindest wesentlich sich gebessert haben, wenn der Kranke an Gewicht zunehmen, Fett ansetzen kann. Da ich dem Umstand Rechnung tragen mußte, daß die weitaus größte Mehrzahl unserer Fälle von außen zugegangen waren, beschränkte sich die Nachuntersuchung auf Einholen brieflicher Mitteilungen, da den Operierten eine oft weite Reise schon aus äußeren Gründen nicht zuzumuten war. Es handelt sich dabei selbstverständlich um die subjektiven Symptome; dieselben haben aber, sowohl für den Arzt als auch für den Kranken, die größte Bedeutung.

Die Gewichtszunahme bietet uns ein relatives und wichtiges Maß für die Qualität des erzielten Erfolges. Sie wird, abgesehen von äußeren Umständen, von der Möglichkeit, sich genügend zu nähren, verschieden sein, je nach dem Grade der vor der Operation bestandenen Abmagerung, von dem Alter und der Größe des Individuums.

Nach Gastroenterostomien kehrt, sagt Rencki, die motorische 
Zur Statistik der Gastroenterostomien bei benignen Magenerkrankungen. 517

Magenfunktion bald, meist innerhalb der ersten vier Wochen, zur Norm zurück, während der Chemismus nicht immer zur Norm zurückkehrt. Die Hyperchlorhydrie schwindet oft (Hartmann u. Soupault), die Dilatation verliert sich, bald schneller, bald langsamer. Auch die Motilität kehrt in den ersten Wochen wieder (Siege, Klemperer). Zu fast gleichen Resultaten kam Dunin. Kausch ${ }^{1}$ ) fand, daß nach Gastroenterostomie die Motilität schnell normal wird, die Aciditätswerte rasch zur Norm oder unter dieselbe sinken, im letzteren Fall bald wieder normal werden, daß aber im Spülwasser nach G.-E. stets Galle als charakteristisches Merkmal der abnormen Kommunikationsverhältnisse gefunden wird, nach $\mathrm{K}$ aiser ${ }^{2}$ ) sogar bei Y-förmiger Gastroenterostomie, ein Vorkommnis, das im allgemeinen als irrelevant zu betrachten ist, während Pankreassekret wenigstens beim Tier im Magen, stets üble Folgen nach sich zieht. Die Hauptwirkung der Gastroenterostomie besteht nach Petersen und Machol in der Erleichterung and Beschleunigung der Magenentleerung, wodurch das Nachlassen der motorischen Insuffizienz, die Beseitigung der Schmerzen, Blutstillung, Sinken der Hyperacidität und Beschleunigung der Spontanheilung bedingt wird.

Von unseren Fällen sind, wie aus Tabelle IV ersichtlich ist, $52 \mathrm{~Pa}$ tienten geheilt entlassen worden. 3 von ihnen starben nachträglich, eine Patientin an multiplen tuberkulösen Stenosen des Dünndarmes und 2 Fälle an Carcinom. Mithin verblieben für die Nachuntersuchung 49 Fälle, 2 blieben verschollen, so daß nur von 47 Fällen Nachrichten über die SchluBbefunde vorliegen.

Als gute Resnltate sind jene zu bezeichnen, bei denen es nach der Operation zu wesentlicher Gewichtszunahme kam und keine oder nur sehr geringe Beschwerden im Anfang nach der Entlassung bestanden, kein Erbrechen und keine Schmerzen vorhanden waren; als mittelgute Erfolge, wo keine effektive Gewichtszunahme, aber keine Schmerzen und kein Erbrechen sich vorfand; als schlechte jene, wo neben gleichbleibendem Gewicht oder gar Gewichtsabnahme noch Schmerzen und Erbrechen fortbestanden. Wenn wir die nachträglich Gestorbenen zu unseren Fällen zuzählen, so haben wir 50 Fälle, von denen Nachrichten vorliegen. 32 Patienten $=64$ Proz. sind als vollkommen und dauernd geheilt zu betrachten, 12 Patienten = 24 Proz. sind mehr oder weniger gebessert, somit sind es

1) 11 Gastroenterostomien: 9 geheilt, 1 gebessert, 1 ungeheilt.

2) 15 Gastroenterostomien: 9 geheilt, 3 gebessert, 2 ungeheilt, 1 verschollen. 
44 Heilungen $=88$ Proz. dauernder Erfolge, 6 Proz. Todesfälle und 6 Proz. Mißerfolge. ${ }^{1}$ )

Die Geheilten zeigen fast ansnahmslos eine bedeutende Gewichtszunahme, die Ernährung geht glatt und anstandslos von statten, die Patienten fühlen sich wohl und sind vielfach sehr erstaunt über das günstige operative Resultat. Die Gewichtszunahme schwankt zwischen $33 \mathrm{~kg}$ in 6 Monaten und $2-3 \mathrm{~kg}$ in 1-2 Jahren. Ein noch günstigeres Resultat zeigt Patient 32. In den ersten zwei Monaten nach der Entlassung nahm Patient rapid um $20 \mathrm{~kg}$ zu, in den folgenden 6 Monaten nur um $3 \mathrm{~kg}$. Auch Patienten, welche nur eine Besserung ihres Leidens haben, zeigen oft ganz bedeutende Gewichtszunahmen.

Mit dem Aussetzen des Erbrechens kommt ein Moment großer psychischer Befriedigung zustande, das Bewußtsein, von einem schweren Leiden befreit zu sein, ruft neue Lebensenergie hervor und damit steigert sich die körperliche Besserung. Wenn man das qualvolle Leiden bedenkt, die förmliche Angst, die die Kranken vor jeder Nahrungsaufnahme haben, berücksichtigt, so wird man erkennen, welch große psychische Unterstützung im Ausbleiben der qualvollen Beschwerden gelegen ist. So mußte ein Patient Prof. Hocheneggs ${ }^{2}$ ), um halbwegs verdauen zu können, bis 9 Liter Wasser trinken.

Es ist nun sehr auffällig und interessant, wie sich in einzelnen Fällen die Gewichtszunahme gestaltet. Bald ist sie nur unbedeutend und steigt allmählich bis zu einer gewissen Höhe, um dann von dieser wieder um einiges zurückzasinken und auf dieser Höhe stationär zu bleiben. In anderen Fällen wieder ist die Gewichtszunahme und der Fettansatz in den ersten Wochen eine rapide, eine überraschend hohe, dann aber bleibt ein langsames allmähliches Ansteigen zu einer gewissen Höhe, auf der das Gewicht dann stationär bleibt. Versucht man, sich diese Erscheinung zu erklären, so können zwei Vorstellungen hierzu herangezogen werden. Einmal ist es das enorme Ausgehungertsein der Patienten. Der Organismus nimmt jedes nur resorbierbare ind zur Assimilation brauchbare Quantum mit dem Höchstprozentsatz der Ausnutzung auf. Ein anderes Moment, das die rapide Gewichtszunahme erklären kann, ist folgendes. Durch die Gastroenterostomiefistel gelangt auch

1) Inzwischen ist bei einer Patientin, die zur Zeit der Nachuntersuchung vor der Pubertät stand und an bedeutenden Beschwerden litt, jetzt vollständige Heilung eingetreten.

2) Offizielles Protokoll der k. k. Gesellschaft der Ärzte vom 26. X. 1906. 
Zur Statistik der Gastroenterostomien bei benignen Magenerkrankungen. $\mathbf{5 1 9}$

Duodenalinhalt, wenigstens teilweise, in den Magen, und die Möglichkeit, den Speisebrei mit den zur Resorption notwendigen Fermenten innig zll mischen, die Resorption derselben wesentlich zu begünstigen, ist hier eine günstigere. Ein weiteres Kriterium der Beurteilung der Leistungsfähigkeit einer Operation ist die Rückkehr der Arbeitsfähigkeit des Einzelindividuums. Hier ist die soziale Stellung des Kranken von Bedeutung. Die schwere Arbeit des Fabrikarbeiters, die Anstrengungen, die der Hochgebirgsjäger auszustehen hat (Fall 9), können wieder geleistet werden.

Bei Franen kommt noch in Frage, ob sie nach überstandenem operativen Eingriff ohne Beschwerden gebären können.

Hier kommt ein Fall aus der Privatpraxis meines Chefs in Betracht. Die Patientin wurde 10. XI. 1898 wegen Ulcus gastroenterostomiert. Zweiter Partus ohne Beschwerden, ausgenommen leichte Magenschmerzen auf der Höhe der Wehentätigkeit.

Bevor ich mich der Besprechung der minder guten Resultate zuwende, muß ich in Betracht ziehen, welche Umstände das Wegfallen des erhofften günstigen Resultates bestimmen. Zunächst kann das Leiden überhaupt ein rein nervöses sein oder mit hysterischen Symptomen kombiniert auftreten. In solchen Fällen ist bald die einfache Probelaparotomie von auffallend günstigem Resultat gefolgt (wir verfügen über drei derartige Fälle) oder das Leiden wird durch den operativen Eingriff verschlechtert. Ferner können Ursachen in der Operation bezw. deren Folgezustände das minder gute Resultat begründen. Ein Nichtfunktionieren der Anastomosenöffnung; ein narbiges Schrumpfen derselben ist selten, viel häufiger sind es sekundäre Veränderungen in der Umgebung der Operationsstelle, Verwachsungen, Stränge, die den ungünstigen Verlauf begründen, besonders dann, wenn bereits früher andere Operationen am Magendarmtrakt vorgenommen worden sind (Fall 37). Wurde die G. E. bei stark dilatiertem Magen zu hoch angelegt, so kann es vorkommen, daß der untere Teil des Magens sich förmlich als Blindsack etabliert und seinen Inhalt nur dann entleert, wenn der Patient eine für den jeweiligen Fall besonders günstige Stellung einnimmt (siehe S. 496 und Fall 15). Endlich können äußere Umstände, die in den Verhältnissen des Patienten selbst liegen, den Grund zu dem minder guten Resultat abgeben.

Wenngleich es durchaus nicht in meiner Absicht liegt, die Statistik auf Grund der Objektivität herauszuschmücken, muß ich doch einige Momente hervorheben, die an einer Beeinträchtigung des Resultates schuldtragend sind. 
In einem Fall ist es ausgesprochene Trunksucht nebst Lebercirrhose, eine Patientin litt zur Zeit der Untersuchung an einer Taenie, eine Patientin, die in den ersten Monaten nach der Operation sich wesentlich erholte, begann dann wieder an häufigem Erbrechen zu leiden, war aber damals im 4. Monat gravide, eine Patientin Jeidet an Lungentuberkulose. Einmal bestanden neben sehr gebesserter Magenfunktion noch Stenoseerscheinungen des Darmes, offenbar durch Verwachsungen bedingt. Da man bei all diesen Fällen das ungünstige oder weniger günstige Resultat von der Operation nicht abtrennen kann, bleibt es notwendig, dieselben als minder gute Erfolge $z u$ betrachten.

Jedenfalls ist der Effekt der G.-E. bisweilen nicht ein unmittelbarer, es vergehen oft viele Tage, bis sich die volle Funktionsfähigkeit einstellt. Nicht zu leugnen ist, daß während dieser Zeit eine gewisse Gefahr besteht. Es kann unmittelbar nach der Operation oder bald darnach zur Perforation und septischer Peritonitis kommen.

So verloren wir vor kurzem (November 1906) einen Fall von Ulcus und Stenose nach der Gastroenterostomie am 4. Tage durch Perforation eines Duodenalulcus, im Perforations-Chok, innerhalb weniger Stunden. Naht suffizient.

Durch das Anlegen der Mucosanaht kann es zu ödematöser Schwellung der zwischen den einzelnen Nähten liegenden Schleimhaut kommen, wodurch das Lumen der Anastomose wesentlich verengt wird. Am Sektionstisch konnte man derartige ödematöse bis kirschengroße, gegen das Lumen der Anastomose vorspringende Anschwellungen der Schleimhaut wiederholt beobachten. Sie kommen wahrscheinlich oft vor, gehen aber gewiß meist bald zurück. Dadurch läßt es sich vielleicht erklären, daß bisweilen nach der Operation einige Tage recht heftige subjektive Symptome des Leidens andauern und erst alimählich schwinden. Auch leichte submucöse Hämatome können zu gleichen Schwierigkeiten Anlaß geben.

Zur Sicherstellung der Funktionsfähigkeit der G.-F.-Fistel wurde in einigen Fällen radiologisch die Füllung der aboralen Schlinge mit schattengebenden Nahrungsmitteln versucht. (Bismuth subnitric in stark gezuckerter Milch oder in Milchbrei verteilt.) Man findet oft schon in kurzer Zeit von der als starker Schatten vortretenden großen Kurvatur einen streifenförmigen meist nach links verlaufenden Schatten, der sich allmählich in der Schattenqualität des Bauches verliert. Tritt diese Frscheinung in einer halben Stunde nach dem Eingeben des Bismutbreies ausgeführten Aufnahme zutage, so kann man wohl die Magendarmfistel als suffizient bezeichnen. Ein negatives Resultat ist natürlich nicht ausschlaggebend. 
Zur Statistik der Gastroenterostomien bei benignen Magenerkrankungen. 521

In Kürze mitgeteilt ist die an unserer Klinik geübte Technik, folgende: nach Vorziehen und Umdrehen des Magens, so daß dessen hintere Fläche sichtbar ist, wird das Mesocolon an einer gefäßfreien Stelle durchtrennt und mit der hinteren Magenwand vernälit. Hierauf wird die an ein Plica duodenojejunalis sich anschließende, nicht gedrehte Dünndarmschlinge, etwa 8-10 $\mathrm{ccm}$ von derselben entfernt, mit Sero-Serosanähten in einer Länge von $6 \mathrm{~cm}$ an die hintere Magenwand fixiert, Magen und Darm eröffnet, die Schleimhäute mit durchgreifenden Nähten vereinigt, vordere durchgreifende Incosanaht, Serosanähte, einige Lembertnähte.

Ein Abschnüren der Dünndarmschlingen, ein nachträgliches Ausspülen der Bauchhöhle werden ebensowenig wie Kochsalzeingießungen geübt. Das ruhige Vorziehen des Magens mit den beiden Ecknähten genügt meist zur Sicherung gegen den Ausfluß von Mageninhalt. Wir verwenden zur Naht nur isolierte Seidenknopfnähte, der Murphyknopf, der an der Heidelberger Klinik einer besonderen Pflege sich erfreut ${ }^{1}$, wird bei uns nicht verwendet. Einmal kann das unangenehme Ereignis eintreten, daß der Knopf in den Magen fällt und hier eventuell bedeutende Beschwerden hervorrufen kann (Kausch, Carle und Fantino, Chlumsky), andererseits kann es zur Perforation mit konsekutiver Peritonitis kommen (Chlumsky, Trendel, Marwedel). Endlich kann der Knopf anch in die adorale Schlinge gelangen und hier wesentliche Beschwerden hervorrufen, die zur Relaparotomie führen (Lauenstein).

Zum nicht geringen Teil aber der Umstand, daßs die bei Knopfanwendung gebildete Kommunikation klein, viel kleiner als die an unserer Klinik geübte ist, veranlassen uns, bei der einfachen Knopfnaht zu bleiben. Die Anastomosenöffnung ist immer $4-5 \mathrm{~cm}$ groß, oval gestaltet. Diese Form der Gastroenterostomie entspricht genau der von Petersen auf Grund anatomisch-topographischer Studien empfohlenen Schlingenanlegung. Dann aber ist auch eine Braunsche Enteroanastomose überflüssig, nach Bake š sogar unausführbar.

Wie schon Lorenz (1903) hervorhob, wurde laut der von Porges (1897) veröffentlichten Mitteilung an den von Hochenegg geleiteten Stationen schon vor Petersen s Mitteilung diese Schlingen-

1). Neuerdings wurde von $\mathrm{Kramer}$ aus der Heidelberger Klinik abermals auf die Vorteile der Anwendung des Knopfes hingewiesen und die Reihe von 99 Fällen hervorgehoben, in denen der Murphyknopf zur Anwendung kam. Das Fehlen einer entsprechend großen Zahl von mit Naht behandelten Fällen, diese Lücke mag durch unsere Reihe von 112 Fällen mit Naht bei 8,92 Proz. Mortalität bezw. von 76 Fällen mit 5,4 Proz. Mortalität ausgefüllt werden. 
anlegung geäbt, eine Methode, der man viele Vorteile, besonders die Vermeidung des Circulus vitiosus, zu verdanken hat. (Lorenz, Chirurgenkongreß 1906.)

Ein bestimmter Anteil des Duodenalinhalts, also Galle, wird sich dabei leicht in den Magen entleeren. Ist derselbe nur gering, so zieht dies keine üblen Folgen nach sich, ja bisweilen findet man erhebliche Mengen von Galle im Magen, ohne daB Beschwerden hervorgerufen werden (Hartmann und Soupault). Nicht nur Tierversuche, sondern auch die von Wickhoff und Angerer und unabhängig von diesen von Terrier ausgeführte Cholecystogastrostomie beweisen dies. Berücksichtigen muß̣ man noch ein gewisses mechanisches Moment, das sich nicht wegleugnen läßt, da der Mageninhalt, dem Gesetze der Schwere folgend, nach unten ${ }^{1}$ ), das ist in die aborale Schlinge, sich entleeren wird, ohne Rücksicht auf die Stellung, die der operierte gerade einnimmt.

Die Frage, kommt es durch eine Gastroenterostomie wirklich zur Ausheilung eines Magengeschwürs, muß auf Grund der bisherigen Erfahrungen, die auf klinischen Untersuchuugen operierter Fälle und auf der wiederholt ausgeführten Antopsie, am Seziertisch und bei notwendig gewordenen Relaparotomien in vivo fußt, entschieden mit ja beantwortet werden. Autopsien bei Relaparotomien haben uns in neuerer Zeit von der Richtigkeit dieser Auffassung überzeugen können (Brenner, Cačkovič). Brenner, ein Verfechter der Exzision des Magengeschwürs, sah sich gezwungen, Patienten, die er wegen callösen Ulcus gastroenterostomiert hatte, zu relaparotomieren (wegen Ventralhernie, Incarceratio interna) und konnte nach einem Jahr ein Ausheilen der Geschwüre beobachten.

Durch die Anlegung einer Magendarmfistel beseitigen wir die bestehende Stagnation, die auch dann besteht, wenn das Geschwür den Pylorus selbst nicht stenosiert. Das Ulcus ruft reflektorisch Spasmus hervor, dem Spasmus folgt Staung, der Stauung Hyperchlorhydrie, Hyperacidität und letztere verhindert zumindest die Heilung des Geschwürs, wenn sie nicht gar zur Bildung neuer Ulcera führt. Man denke an den Sphinkterkrampf bei Fissuren und an den Vaginismus. $\mathrm{Ja}_{\mathrm{a}}$ es ist nicht ganz ausgeschlossen, daß der Pylorospasmus das primäre Moment darstellt. Talma hat durch Duodenumligatur Infarkte der Schleimhaut des Magens erzielt und führt das Entstehen der Ulcera auf diese

1) „Quand le pylore est rétréci ou fermé et que la gastroenterostomie a crée un nouvel orifice de communication avec l'intestin ... la resultante des contractions stomacales a pour l'effet de chasser les aliments ... directement d'arrière en avant. ... Le prétendu isopéristaltisme de l'estomac et de l'intestine vers à droite n'existe plus" (Fritz de Beule). 
Zur Statistik der Gastroenterostomien bei benignen Magenerkrankungen. 523

Blutungen zurück. Andererseits können spontane embolische oder thrombotische Prozesse die Veranlassung zur Ulcusbildung bieten (Hausner, Virchow).

Beseitigen wir die Staumng, so fällt die Hyperchlorhydrie meist weg und damit das Moment, das der Ausheilung eines Geschwürs im Wege steht. Renki fand, daß nach G.-E. die motorische Funktion bald, meist innerhalb der ersten 4 Wochen zur Norm zurückkehrt (Klemperer, Siegel), nicht immer aber der Chemismus, die Hyperchlorhydrie schwindet meist. Die Gasbildung, die nach Kuhn eine Folge der Stagnation des Mageninhalts ist, wird selbstverständlich, da nun mechanisch günstige Abflußbedingungen geboten sind, ebenfalls zurückgehen. Ebenso verhält es sich nach Boas mit dem MagensaftfuB. Kausch fand, daß nach Gastroenterostomien die Mortalität schnell zur Norm zurückkehrt, die Aciditätswerte schnell zur Norm oder sogar unter dieselbe sinken, im letzteren Fall bald wieder normal werden, daß aber als charakteristisches Merkmal stets Galle im Magen sich findet, was aber bei geringen Quantitäten derselben im allgemeinen irrelevant ist, vielleicht sogar einen günstigen Einfluß hat.

Beseitigen wir den Spasmus des Pylorus durch eine Plastik oder durch die Lorettasche Divulsion so sind wir nicht vor Rezidiven geschützt, ebensowenig wie bei einer Exzision des Ulcus, um so mehr als wir nicht wissen können, ob es nicht neuerdings zur Schrumpfung des Narbengewebes kommt. Die Resektion schützt nicht vor Rezidiven, man kann dabei auch ein zweites Ulcus übersehen, das weiter seine deleläre Wirkung ausübt. ')

Die Resektion oder die Exzision hat in letzter Zeit zwar in Jedlicka, Bakes, Ali Krogius und Rydigier (1906) ihre Verfechter gefunden, besonders beruft sich Ali Krogius auf die ihm wiederholt untergekommene postoperative letale Blutung nach Gastroenterostomie, ein Ereignis, das auch nach Exzision eines Geschwüres aus einem zweiten, bei der Operation nicht gefundenen Ulcus eintreten kann (Braun). „Die relative große Zahl von Todesfällen, die Ursachen derselben, sprechen deutlich gegen die Exzision" (Lieblein-Hilgenreiner).

Die Versuche, auf experimentellem Wege die Frage zu lösen, wurden durch die Experimente Fibichs ${ }^{2}$ ) in einem für die G.-E.

1) Hacker erklärte 1892, „daß er die Hauptbedeutung der Gastroenterostomie gerade in der Behandlung gutartiger Magenerkrankungen sehe, da die Gefahren der Resektion wegen Ulcusnarben und Stenosen recht große seien und diese Operation vor dem Wiederauftreten an anderer Stelle nicht schütze."

2) In bezug auf genaue experimentelle Technik sei auf die Arbeit Fibichs verwieseu. Langenbecks Arch., Bd. 79. 
sprechenden Sinne entschieden. Fibich konnte durch Versuche an Hunden nachweisen, daß man durch Unterbindung von Gefäßen, Exzision der von ihnen versorgten Schleimhant und Kauterisation des Defektes, Geschwüre hervorrufen kann, die der Heilungstendenz entbehrend, dem primären Magenulcus gleichen und erst nach Ausführung einer G.-E. zur Heilung gelangen. Steter leichter Abfluß des Magensaftes genügt nicht, die Ulcera zur Ausheilung zu bringen, dazu ist wahrscheinlich noch der Wegfall des reflektorischen Pyloruskrampfes notwendig.

Die Entlastung des geblähten Magens scheint auch einen günstigen Einfluß anf eine gerade bestehende Magenblutung zu haben. Wie schwer es ist, eine Blutung zu beherrschen, das Geschwür und das blutende Gefäß zu finden, und wenn man es gefunden hat, die Blutung zu beherrschen, wird allseits hervorgehoben. Allein selbst bei bedeutenden Blutungen dürfte die Ausführung der G.-E. einen günstigen Einfluß haben, zumindest sprechen die klinischen Erfahrungen dafür. Man braucht den dilatierten gefüllten Magen nur in Analogie zu bringen mit einer Blase, in die eine Blutung erfolgt und die durch Entleerung und Kontraktion ihrer Wandung die Blutung spontan stillt, oder den Vorgang mit einer Rektalblutung zu vergleichen, wo alle Tamponade nichts nützt, wenn man nicht durch ein über den Tampon ragendes Drain die Gasblähung vermeidet.

$\mathrm{Zu}$ den Gefahren, die durch einen chirurgischen Eingriff, wie ihn die G.-E. darstellt, heraufbeschworen werden können, gehört das Ulcus peptic. jejuni.

Braun hat im Jahre 1899 die erste Mitteilung über das Vorkommen eines peptischen Jejunalgeschwüres nach einer Gastroenterostomie bekannt gegeben. Damals am Chirurgenkongreß 1899 hat auch Hahn über eine analoge Beobachtung berichtet. ') Im Jahre 1900 waren 3 sichere Fälle bekannt(Braun, Hahn, Mikulicz). Körte steltte 1900 den 4. Fall am Chirurgenkongreß vor, entstanden 3 Jahre nach einer Wölflerschen Gastroenterostomie, Steinthal ein solches, das 10 Tage nach der Operation entstand. Tiegel berichtete 1904 über 22 Fälle aus der Literatur, Lieblein erwähnt mit den 3 Fällen von Cačkovič und zwei Fällen von May.o Rob-

1) In der Arbeit von Kausch 1899 finden wir einen Fall erwähnt, wo es nach einer G. ant. antec. mit $50 \mathrm{~cm}$ langer Schlinge später zur Bildung eines Geschwürs an der Anastomosenstelle mit Übergreifen auf das Jejunum kam. Wir können auch diesen Fall als Ulc. pept. jejuni bezeichnen. 
Zur Statistik der Gastroenterostomien bei benignen Magenerkrankungen. 525

son 27, Delaloye 1906 fügte einen netten hinzu. Nach dessen Zusammenstellung fand sich das Ulens

bei Gastroenterostomia anterior $22 \mathrm{mal}$
1mal nicht angegeben.

Gosset hat vor einigen Monaten 31 Fälle gesammelt. In der Art der Gastroenterostomie erblickt Gosset keinen Grund für das Entstehen dieser postoperativen Erkrankung. Sie kann ebenso bei einer vorderen, wie bei einer hinteren Gastroenterostomie auftreten. Nach Gossets Zusammenstellung war das Ulcus peptic. jej. $15 \mathrm{mal}$ nach einer Wölflerschen, 4 mal nach einer solchen mit Enteroanastomose nach Braun, einmal nach einer Y-förmigen Gastroenterostomie aufgetreten. In 6 Fällen war eine v. Hackersche Gastroenterostomie dem Ausbruch des Geschwüres vorausgeschickt worden, einmal eine Gastroent. post. mit Enteroanastomose.

Als Ursache wird im allgemeinen die Hyperacidität des Magensaftes angenommen. „Dadurch daß die Salzsäure des Magensaftes mit einem Abschnitt des Digestionstraktus in innige Wechselwirkung gebracht wird, welcher überhaupt für die Aufnahme saurer Massen nicht geeignet ist, wird die Gefahr eines Ulcus peptic. jejuni heraufbeschworen." Es gibt allerdings in der Literatur einige Beobachtungen die nicht hyperaciden Mageninhalt hatten ${ }^{1}$ ), allein es ist nicht klar, ob ein solcher zur Zeit unmittelbar vor dem Ausbruche des Leidens bestand. Wir müssen beim Ulcus peptic. jejuni, sagt Lieblein, annehmen, dals der peptische Magensaft seine Wirkung erst dann geltend macht, wenn durch eine vorausgegangene Nekrose eines Schleimhautbezirkes der Boden für eine Autolyse gegeben ist."

Die Gefahr des Ulcus peptic. jejuni ist gewiß keine zu verachtende, selbst wenn man annimmt, daß das prozentuelle Verhältnis dieser Affektion zu den recht häufig ausgeführten Gastroenterostomien ein geringes sein dürfte. Gewiß kommt diese Komplikation viel häufiger bei der vorderen nnd bei den mit Enteroanastomose kombinierten Gastroenterostomien zustande als bei den einfachen hinteren Anastomosen.

Nach Kellings Untersuchungen an Tieren kann es keinem Zweifel unterliegen, daß Salzsäurelösungen vom Duodenum aus einen momentanen Gallenzufluß bewirken, hingegen von einer Jejunumschlinge aus, welche, proportional gemessen, so gewählt wird,

1) Kocher, Mikulicz, Haidenhain. 
daß sie der abführenden Schlinge einer in $50 \mathrm{~cm}$ von der Plica duodenojej. ausgeführten G.-E. beim Menschen entspricht, erfolgt dies nicht mehr. Es ist daher klar, daß der Gallenzufluß ein besserer sein wird bei einer kurzen Schlinge als bei einer langen. Der Reflex, der nach Einwirkung des sauren Mageninhaltes prompten Zufluß von Galle auslöst, wird um so geringer sein, je länger der adorale Schenkel der G.-E. ist, zugleich aber wird die Empfindlichkeit dieser Schleimhautpartie gegenüber dem sauren Magensaft eine größere sein als an einer mehr adoralen Partie. Berücksichtigen wir nun das viel häufigere Vorkommen eines peptischen postoperativen Jejunalgeschwüres bei G.-E., bei denen eine lange Dünndarmschlinge gewählt wurde (vordere), bedenken wir fermer, daß der Zufluß von Galle in den Magen nicht nur die Funktionen des Magens nicht wesentlich beeinträchtigt, ja vielleicht durch teilweise Neutralisation des hyperaciden Mageninhaltes die Heilung eines Magengeschwüres begünstigt, so können wir jener Gastroenterostomie das Wort reden, die mit einer möglichst kurzen Darmschlinge ausgeführt wird, zugleich eine Gastroenterostomie, bei der der Kontakt der Dünndarmschleimhaut mit Galle durch eine Enteroanastomose nicht ausgeschaltet wird (Li eblein-Hilgen reiner). Diesen Anforderungen entspricht am ehesten die von Hochenegg und Petersen empfohlene Methode.

Tatsächlich haben wir an unserer Klinik seit Einführung dieser Methode weder einen Circulus vitiosus noch ein postoperatives peptisches Jejunalgeschwür je zu beobachten Gelegenheit gehabt. ${ }^{1}{ }^{2}$ )

Mithin können wir auf Grund unserer Beobachtungen sagen:

I. Die operativen Verluste bei Gastroenterostomien betragen zirka 5-7 Proz.

II. Die Spätresultate entsprechen 88 Proz. Erfolgen (64 Proz. völlige Heilung, 24 Proz. Besserung).

1) Ebenso berichtet Kramer aus der Heidelberger Klivik, daß dortselbst kein Circul. vitiosus beobachtet wurde. Die Heidelberger Klinik verwendet bekanntlich die Methode Petersens.

2) Der Vorschlag Gossets, eine G.-E. fondosa zur Verhinderung des Uleus peptic. auszuführen, erscheint auf Grund dieser Erwägungen nicht nur unrichtig, sondern sogar gefährlich. Die Schlinge, die zur Anastomose verwendet wird, müßte dann bedeutend länger sein, als wir es wünschen, und gerade das, was wir vermeiden wollen, die Berieselung gegen aciden Magensaft hochempfindlicher Dünndarmschleimhaut, würde hierdurch nur begünstigt werden. 
Zur Statistik der Gastroenterostomien bei benignen Magenerkrankungen. 527

III. Durch eine Gastroenterostomie werden nicht nur Stenoseerscheinungen behoben, sondern auch Geschwüre zur Ausheilung gebracht.

IV. Unter allen Gastroenterostomien ist die mit einer kurzen, nicht gedrehten, an der Rückseite des Magens befestigten Schlinge ausgeführte Anastomose am meisten zu empfehlen (Hochenegg-Petersen), da sie

1. Den normalen topographisch-anatomischen Verhältnissen am ehesten entspricht.

2. Den Circulus vitiosus am ehesten zuvermeidenvermag.

3. Auf Grund theoretischer Erwägungen der Entstehung eines postoperativen peptischen Jejunalgeschwüres zu begegnen imstande ist und

4. Am ehesten geeignet erscheint, die Ausheilung eines Magengeschwüres zu begünstigen.

\section{Krankengeschichten. Männer (32 Fälle).}

Fall 1. K. S., 59 J., Kutscher aufgenommen 30. X. 1903 . Vor etwa 2 oder 3 Jahren begann Patient an Magenbeschwerden zu leiden. Druck und Völle in der Magengegend, weder Spontanschmerzen noch Erbrechen. Stuhl angehalten. Ein Jahr später Verschlechterung mit krampf haften Schmerzen, Aufstoßen, Erbrechen 3-4 Stunden nach dem Essen. Vom Oktober 1902 bis Januar 1903 ärztliche Behandlung auf einer internen Station. Besserung, Oltober 1903 neuerliche Beschwerden mit Erbrechen saurer Massen. Nie blutiges Erbrechen. Potator.

Status praesens: Gut genährtes Individuum. Innere Organe normal. Abdomen in der Magengegend auf Druck etwas empfindlich. Magenplätschern bei stoßweißer Palpation. Magen reicht zwei Fingerbreiten unter den Nabel. Kein Tumor $\mathrm{HCl}+3 \cdot 3$ Proz. Milchsäure.

6. XI. 1903. Gastroenterostomia retrocolica post. Pylorus durch sehnige Narben stenosiert. 23. XI. Nach afebrilem Verlauf geheilt entJassen.

Januar 1906 stellt sich Pat. vor. Er hat seit der Operation nicht erbrochen, leidet trotz eines unregelmäßigen Lebens nicht an Magenbeschwerden. Stuhl angehalten. Körpergewicht vor der Operation 74, jetzt 90 Kilogramm.

Fall 2. H. K., 40 J., Fleischhauer, aufgenommen 28. XII. 1903. Vor 5 Jahren eine nicht penetrierende Stichverletzung der Bauchdecken. Seit 3 Monaten leidet Pat. an Erbrechen, meist 1/4 Stunde nach dem Essen, manchmal 2-6 Stunden später. Reichlich Schleim. Keine Spontanschmerzen. Abmagerung um $20 \mathrm{~kg}$ in 3 Monaten.

Status praesens: Subikterisches Kolorit. Chronisches Ekzem des ganzen Körpers. Chronische Pharyngitis. Im Epigastrium undeutliche 
Resistenz. Deutliches Plätschern bei Erschütterung des ganzen Körpers. Im Mageninhalt kein Blut. $\mathrm{HCl}$-, Milchdrüse +. Acidität $49^{0}{ }_{00}$ Gram + Stäbchen, keine Sarcin.

30. XII. 1903. Operation. Mächtig entwickelte Narbe am Pylorus die das Lumen desselben fast völlig verschlieBt. Sehnig glänzendes Narbengewebe, zahlreiche perigastritische Adhäsionen, die den Pylorus zur Porta hepatis ziehen und mit Dünndarmschlingen verlöten. Kein Anhaltspunkt für Carc. keine Drüsen. Gastroenterostomia retrocolica poster.

16. I. 1904. Nach afebrilem Verlauf geheilt entlassen.

10. VIII. 1904. Gestorben an einem Magenleiden (Carcinom?).

Fall 3. K. K., 40 J., Eisengießer, aufgenommen 16. I. 1904. Erste Beschwerden 1889. Gefühl von Völle, Erbrechen, nach 14 Tagen spontane Besserung bis vor 3 Jahren; stechende Schmerzen in der Magengegend, gefolgt von Erbrechen 4-5mal täglich, einigemal mit Blut gemengt. Stuhl immer angehalten teerschwarz. Seit zwei Monaten nur Milch als Nahrung. Innerhalb von 14 Tagen angeblich um $14 \mathrm{~kg}$ abgemagert.

Status praesens: Thoraxorgane normal. Am Abdomen palpatorisch keine Resistenz. Deutliches Plätschern. Probefrühstück unverdaut. $\mathrm{HCl}+$, Milchsäure --. Körpergewicht $54,5 \mathrm{~kg}$.

Operation 19. I. Narbige Pylorusstenose. Hyperämische Magenwand. Gastroenterostomia retroc. post.

24. I. 1904 geheilt entlassen. Gewicht $56 \mathrm{~kg}$.

Juli 1906 berichtet Patient. Vollkommenes Wohlbefinden. März 1904 einmal galliges Erbrechen. Sonst so wohl wie noch nie. Körpergewicht gegenwärtig $68 \mathrm{~kg}$.

Fall 4. E. K., 53 J., Sollizitator, aufgenommen 2. IIJ. 1904. Die ersten Beschwerden, bestehend in saurem AufstoBen, Sodbrennen und einem dumpfen Schmerz in der Magengegend, vor 23 Jahren. Die Beschwerden hörten nach einiger Zeit spontan auf um zirka nach $1 / 2 \mathrm{Jahr}$ wieder aufzutreten. Steter Wechsel von Erkrankung und Besserung durch 15 Jahre, dann 5 Jahre normales Befinden. Seit etwas über 2 Jahre neuerliche Beschwerden mit kolikartigen Schmerzen, besonders nachts. Gewichtsverlust in letzter Zeit ca. $10 \mathrm{~kg}$. Nie Blut erbrochen.

Status praesens: In der Höhe des Nabels eine quere glatte verschiebliche Resistenz. Magenplätschern. Druckschmerz am Nabel. $\mathrm{HCl}+$, Milchsäure -.

6. III. Operation: Ulcusnarbe. Gastroenterostomia retrocol. post. 21. III. 1904 geheilt entlassen.

Januar 1906 stellt sich Pat. vor, sieht blühend aus. Gewichtszunahme bedeutend, aber nicht eruierbar (gegenwärtig $78 \mathrm{~kg}$ ). Objektiv kein Tumor, keine Magendilatation.

Fall 5. F. M., 22 J., Rotgerber, aufgenommen 14. III. 1904. Leiden dauert seit Jahren. Kolikartige Schmerzen. Nie Bluterbrechen, nie blutige Stühle. Vor 5 Jahren trank Pat. KHO. Pat. beobachtete dann 8 Tage lang Milchdiät. Beschwerden dauerten fort. Interne Behandlung im Dezember 1903 und März 1904 ohne Erfolg.

Status praesens: In der Mittellinie des Bauches bis unterhalb des Nabels Druckschmerzhaftigkeit. Plätschergeräusche. 
Zur Statistik der Gastroenterostomien bei benignen Magenerkrankungen. 529

18. III. 1904 Operation. Cicatricielle Stenose. Gastroenterostomia retroc. post. 5. IV. Nach durch peritoneale Reizung getrübtem Verlauf geheilt entlassen.

11. I. 1906. Brief. Erste Zeit nach der Operation glänzender Zustand, jetzt leichte Magenbeschwerden bei schwerer Kost. Gewichtszanahme $2 \mathrm{~kg}$.

Fall 6. J. Z., 61 J., Zimmermann, aufgenommen Juni 1904. Seit 24 Jahren magenleidend, meist bei nüchternem Magen. Nie Erbrechen. Karlsbader Kur ohne Erfolg. Schmerzen wurden immer häufiger, dann spontane leichte Besserung ohne völliges Schwinden der Schmerzen. Januar 1904. Neuerliche heftige Beschwerden mit Erbrechen.

Status praesens: Abdomen etwas aufgetrieben, nirgends eine Resistenz. Perkutorisch gleichmäßiger Schall. Magenplätschern, Magensteifung. Kapazität $3000 \mathrm{ccm} . \mathrm{HCl}+3 \%$, Milchsäure - Gewicht $46 \mathrm{~kg}$.

14. VI. 1904 Operation. Magen dilatiert. Am Fundus Verdickungen. Netzadhäsionen. Pylorus durch ein Infiltrat stenosiert und an die Leber fixiert. Gastroenterostomia retrocol. post. anisoperist.

24. VI. Per primam. 2. VII. 1904 mit $531 / 2 \mathrm{~kg}$ geheilt entlassen.

0 ktober 1904. Wohlbefinden. $56 \mathrm{~kg}$ Gewicht.

Januar 1906. Vollständig gesund. Gewicht stationär. (Es wundert mich, daß mir das schmerzvolle Leiden durch die Operation völlig genommen wurde, schreibt Patient.)

Fall 7. J. G., 39 J., Taglöhner, aufgenommen 11. VI. 1904. Magenbeschwerden begannen vor 6 Jahren mit AufstoBen, Übelkeit und Erbrechen 1-1/2 Stunden nach dem Essen; dann Erleichterung. Nach 6 Wochen etwas Besserung, doch wiederholte sich das Leiden mehrmal jährlich, 2-6 Monate dauernd. Nie Blut im Erbrechen oder im Stuhl.

Status praesens: Diastase der Rekti. Am Pylorusgeringe druckempfindliche Resistenz. Lautes Magenplätschern. $\mathrm{HCl}+$, Milchsäure -

17. VI. Operation. Narbige Stenose des Pylorus für kaum den Kleinfinger durchgängig. Adhäsionen mit Leber und Colon. Gastroenterost. retrocol. post. aniso.

6. VII. 1904. Geheilt entlassen.

13. I. 1906. Briefliche Anfrage: Vollständiges Wohlbefinden. (Mein Leiden kenne ich nicht mehr, schreibt Pat.) Gewichtszunahme $14 \mathrm{~kg}$.

Fall 8. J. Sch., 30 J., Straßenkehrer, aufgenommen 27. VII. 1904. Vor 3 Jahren plötzlich mit heftigen Schmerzen und Erbrechen erkrankt. Nach Milchdiät Besserung. Unangenehmes Gefühl der Völle blieb bestehen. Vor 2 Jahren bemerkte der Pat. dunkles Blut dem Stuhl beigemengt. Seit 2 Monaten Verschlechterung.

Status praesens: Magendilatation, Plätschern.

1. VIII. 1904. Magen gebläht, Pylorus fixiert, stenosiert. Netz mit der vorderen Bauchwand verwachsen. Gastroenterostomia retroc. post. isoperist. haltend.

1. VIII. Blutiges Erbrechen. Adrenalin. 4. VIII. Erbrechen an- 
6. VIII. 1904. Relaparotomie. Blähung der zuführenden Darmschlinge. Dieselbe mit Galle gefüllt. Daher Braunsche Anastomose.

5. VIII. 1906. Erbrechen anhaltend. 9. VIII. Erbrechen sistiert. 19. VIII. Geheilt entlassen.

Januar 1906. Subjektiv keine Beschwerden. Gewichtszunahme, Höhe derselben nicht bekannt.

Fall 9. J. R., 52 J., Förster. 4. VII. 1904. Vor 13 Jahren zum erstenmal Druck und Völle im Magen, besonders nach den Mahlzeiten, so intensiv, daß Patient, um sich Erleichterung zu schaffen, absichtlich Erbrechen herbeiführte. Reichlich stark saures Erbrechen von Flüssigkeit, die an Quantität die eingenommene Mahlzeit stets übertraf. Die Erleichterung war gewöhnlich nur von kurzer Dauer. Diese Beschwerden dauerten 3 Wochen, eine gewisse Empfindlichkeit gegen DiätverstöBe blieb aber lange bestehen. Der Wechsel zwischen Verschlechterung und Besserung wiederholte sich mehrmals. Wiederholte ärztliche interne Behandlung resultatlos. Im Dezember 1903 zum erstenmal Magenausspülungen. die eine leichte Besserung brachten. Seit Januar 1904 spült sich Patient selbst den Magen aus. In der letzten Zeit hat das Erbrochene einen aashaften Geruch angenommen. Nie Bluterbrechen.

Status: In der Magengegend keine Resistenz. Bei stoßweiser Palpation deutliches Magenplätschern des dilatierten Magens.

7. VII. 1904. Magen enorm gebläht und erweitert, Pylorus durch eine alte Ulcusnarbe stenosiert. Gastroenterostomia retrocolia posterior. 23. VII. Geheilt entlassen.

12. I. 1906. Briefliche Anfrage: Keine Beschwerden, vollständige Gesundung. Gewichtszunahme $3-4 \mathrm{~kg}$.

August 1906 von Prof. Hochenegg nachuntersucht. Vollständige Heilung. Völlige Leistungsfähigkeit selbst bei anstrengendsten Gebirgsjagden.

Fall 10. A. 0., 27 J., Geistlicher. 11. VII. 1904. Seit 7 Jahren Magenbeschwerden, Druckgefühl und Aufstoßen, zeitweise Besserung. Seit Oktober 1903 Beschwerden stärker, Geschmack nach Blut im Munde. Methodische Magenausspülungen, resultatlos. Nie Erbrechen.

Status: Magen reicht zwei Finger unter den Nabel, kein Tumor zu tasten, deutliches Magenplätschern. Magenkapazität $2500 \mathrm{ccm}$. Mageninhalt sauer. $\mathrm{HCl}+$, Milchsäure -

13. VII. Operation. Perigastritische Verwachsungen am Netz und an der Gallenblase. Gastroenterostomia retrocolica posterior.

27. VII. 1904. Geheilt entlassen. $521 / 2 \mathrm{~kg}$.

Februar 1905 teilt Patient mit, sich völlig wohl zu befinden. Gewichtszunahme $8 \% / 2 \mathrm{~kg}$.

11. I. 1906. Leichte Magenbeschwerden, besonders nach Tisch. Leichte Schmerzen in der Narbe. Bei vorsichtiger Kost guter Zustand. Gewichtszunahme im ganzen $10 \mathrm{~kg}$.

Fall 11. N. M., 25 J., Hofkutscher. 16. VII. 1904. Im November 1903 mit heftigen Schmerzen in der Magengegend und mit Bluterbrechen erkrankt. Erbrechen meist einige Zeit nach dem Essen, vorhergehend saures Aufstoßen und Schmerzen. 
Zur Statistik der Gastroenterostomien bei benignen Magenerkrankungen. $\mathbf{5 3 1}$

Status: Adomen nicht aufgetrieben, kein Tumor. Magen dilatiert, Magenplätschern. $\mathrm{HCl}+$, Milchsäure -

Operation 22. VII. 1904. Magen dilatiert. Am Pylorus perigastritische Verwachsungen mit Leber und Gallenblase, Pylorus geknickt und durch eine Narbe verengt. Gastroenterostomia retrocolica post.

Afebriler Verlauf. 6. VIII. 1904. Geheilt entlassen.

Nach der Operation nahm Patient in 6 Monaten $24 \mathrm{~kg}$ zu (86 kg), jetzt leichte Abmagerung auf $74 \mathrm{~kg}$. Vollständiges Wohlbefinden.

Fall 12. F. P., 31 J., Wagnergehilfe. 1898 mit Magenschmerz und Erbrechen erkrankt (8 Tage). 1900 heftige Magenschmerzen und Erbrechen, die den Pat. zu einem 3 monatlichen Krankenlager zwangen. Dann 3 Wochen Wohlbefinden. Hierauf neuerlich 9 Wochen lang dieselben Symptome. Dabei Gewichtsabnahme um $19 \mathrm{~kg}$. Pat. stand in ambulatorischer Behandlung verschiedener interner Kliniken ohne Resultat. Die ganze Zeit krampfartige Schmerzen mit Erbrechen abwechselnd. Nie Bluterbrochen.

Status: Im Abdomen nichts Pathologisches nachweisbar. $\mathrm{HCl}+$ Milchsäure -.

Operation 21. X. 1904. Am Pylorus ein etwa kronenstückgroßes Ulcus mit callösen Rändern, geringgradige perigastritische Verwachsungen. Gastroenterostomia retrocolica posterior.

4. X, 1904. Geheilt entlassen.

Januar 1906. Patient sieht blühend aus. Narbe etwas schwächlich. Kein pathologischer Befund nachweisbar. Gewicht ca. $60 \mathrm{~kg}$.

Fall 13. J. H., 32 J., Hoteldiener, aufgenommen 8. XI. 1904. Im Frühjahr 1899 erhielt Patient einen heftigen StoB in die Magengegend durch die Kurbel eines rotierenden Rades. Darauf heftige Schmerzen, die aber nach 24 Stunden aufhörten. Ein halbes Jahr später stellte sich Appetitlosigkeit und Druckgefühl im Magen ein, das sich 1-2 Stunden nach dem Essen zu heftigen Schmerzen steigerte. Dieselben waren bei Linkslage am stärksten bei Rechts- und Bauchlage geringer. Kein Erbrechen. Karlsbader Kur ohne Erfolg. Erkrankung dauerte 14 Tage. Einige Monate später dieselben Beschwerden, die nach 3 Wochen neuerdings verschwanden. Dies wiederholte sich im Laufe der Jahre öfters, 3-4 mal jährlich. Sechs Wochen vor der Aufnahme traten heftige Schmerzen und Erbrechen auf, die sich täglich 1-2 Stunden nach dem Essen wiederholten. Nach dem Essen wurden die Schmerzen geringer, ohne jedoch je ganz aufzuhören. Der Stuhl war dabei angehalten von teerschwarzer Farbe. Vor 14 Tagen Blut in Stuhl, nie Hämatemesis.

Status: Abdomen vorgewölbt druckempfindlich. Rechts oberhalb des Magens, entsprechend dem Pylorus palpiert man eine besonders empfindliche Resistenz. $\mathrm{HCl}+$, Milchsäure -. Blut Erythroc. 5600000 , Leukocyten 88000 , Fleisch 85 Proz.

19. XI. 1904 Operation. Am Pylorus entsprechend dem palpierten Tumor ein derbes, den Pylorus verengendes Narbengewebe; kein Ca. Gastroenterostomia retrocolica posterior.

26. XI. Wiederboltes Erbrechen.

Erbrechen dauerte bis 6. XII. an. Am 8. XII. entlassen. 
Nach der Entlassung trat das Erbrechen neuerdings auf. Erbrechen kaffeesatzartiger Massen mit grunlich bitterem Schleim gemengt.

10. III. 1905 läßt sich Patient neuerdings aufnehmen.

Status: Abgemagert, blaß, subikterisch. Magenplätschern. $\mathrm{HCl}+$, Milchsäure +.

17. III. 1905 Operation. Die Ulcusnarbe erscheint gegen früher unverändert. Keine Drüsen. Pylorus fast undurchgängig, Adhäsionen mit der Leber. Ulcusnarben. Isoperistaltische Gastroenterostomie. Es wird jetzt die Gastroenterostomia antecolia anterior an einer ca. $40 \mathrm{~cm}$ von der Plica duodenojejunalis entfernten Darmschlinge ausgeführt mit Enteroanastomose beider zu- und abführenden Schenkel.

Verlauf durch Bronchitis kompliziert. Nie erbrochen.

14. IV. Geheilt entlassen.

6. I. 1906 neuerliche Spitalaufnahme. Patient fühlt sich vollkommen wohl, kein Erbrechen. Verträgt alles gut. Gegenwärtig besteht eine leichte Infiltration in der Umgebung der Operationsnarbe; sonst vollständiges Wohlbefinden.

Fall 14. F. St., 40 J., Taglöhner. Erkrankung dauert zwei Jahre. Anfangs bestanden nur Schmerzen und Sodbrennen. Seit Juli 1904 tägliches kaffeesatzartiges Erbrechen. Stühle schwarz.

Status praesens: AuBer deutlichem Magenplätschern objektiver Befund negativ. Kapazität $1500 . \mathrm{HCl}+$, Milchsäure -.

5. XII. 1904 0peration. An der kleinen Kurvatur gegen den Pylorus zu eine narbige Einziehung. Im Lig. hepatocolic. kleine Drüsen. Gastroenterost. retroc. post. anisoperist.

20. XII. 1904. Geheilt entlassen.

Die histologische Untersuchung der exstirpierten Drüschen zeigt entzündliche Hyperplasie.

Januar 1906. Einige Monate lang bestand Druckgefül im Magen, seit Mai 1905 vollständiges Wohlbefinden, Gewichtszunahme $10 \mathrm{~kg}$.

Fall 15. R. A., 35 J. Zutransferiert 10. XII. 1904.

Patient stand vom 26. XI. bis 10. XII. 1904 in Behandlung der II. medizinischen Klinils und wurde mit Cholelithiasis und Adhäsionsbildung nach Ulcus ventriculi bzw. duodeni, auf die II. chir. Klinik transferiert.

Im Jahre 1902 litt Patient an drückenden Schmerzen in der Magengegend, besonders nachts, von denen nur Erbrechen Erleichterung schaffte. Ärztliche Behandlung wegen Ulcus ventriculi, trotzdem dauern die Beschwerden fort. Dieselben beginnen stets an einem Punkte rechts in der Parasternallinie, sind druckender Natur und so heftig, daB Atembeklemmungen eintreten. Das Erbrochene enthielt zuerst die Reste der genossenen Mahlzeit, dann kaffeesatzartige Massen. Nach 6 Wochen Erleichterung auf einige Monate, dann neuerliche Beschwerden. Im April 1903 hatte Patient das Gefühl eines Fremdkörpers im Bauche, am andern Tage schwerer Ikterus, der nach 5 Tagen zurückging. Während dieser Zeit war der Stuhl grau, sehr übelriechend.

Juli 1903. Zwei ähnliche Anfälle, später noch Oktober 1903, Juli und November 1904.

Status: Rechts unterhalb des Rippenbogens eine empfindliche Stelle, 
Gallenblase vergrößert, Magen dilatiert. Nach dem Probefrühstück ergibt die Untersuchung des Mageninhaltes: Gesamtacidität $25 \% \mathrm{HCl}+$, Milchsäure - Harn: Zucker + (in Spuren). Gallenfarbstoff + .

19. XII. Operation: Mediane Laparotomie. Zunächst stöBt man auf die stark gefüllte konkrementhaltige Gallenblase. Um sie gut vorzuziehen, wird ein auf den ersten senkrecht nach rechts ziehender Schnitt ausgeführt. Da die Gallenblase durch starke perigastrische Adhäsionen fixiert erscheint, wird von einer Exstirpation alygesehen, die Gallenblase eröffnet und aus ihr sehr viele, kaum erbengroße Konkremente entfernt, die Gallenblase dann durch 3 Etagen Seidenknopfnähte vernäht. Starke Ulcusnarbe am Magen (Stenosis pylori). Gastroenterostomia retroc. post. Drain zur Gallenblase, bis zum 31. XII. afebriler Verlauf. An diesem Tage heftiger Schüttelfrost, neuerliche Drainage. Sekretion reichlich.

1. I. 1905. Fieberfrei.

7. I. 1905 . Sekretion gering.

16. I, 1905. Geheilt entlassen.

16. I. 1906. Briefliche Anfrage: Leichtes Magendrücken nach dem Essen, kein Erbrechen. Wenn Pat. 1/4 Stunde nach der Mahlzeit ruht, schwinden die Beschwerden völlig. Gewichtzunahme zirka $10 \mathrm{~kg}$. Kein Aufstoßen trotz angestrengtester, oft 14 stündiger Arbeit.

Fall 16. W. S., 44 J., Agent. Aufgenommen 16. Il. 1905. Vor 20 Jahren plötzlich einsetzende Magenbeschwerden in Form krampfartiger Schmerzen mit häufigem Erbrechen durch 1/2 Jahr. Dann Wohlbefinden bis vor 6 Jahren; neuerdings Magenbeschwerden, hie und da auch Erbrechen, Gefühl von Völle nach jeder Mahlzeit. Nie Blut erbrochen. Verschiedene interne Medikationen ohne Erfolg. Stuhl andauernd angehalten.

Status: Magen bis 3 Querfinger unter die Nabelhorizontale reichend. Magenplätschern, kein Tumor; HCl -, Milchsäure -

Operation: 21. II. 1905. Magen bedeutend erweitert, in nächster Nähe des Pylorus eine strahlige Narbe. Gastroenterostomia retrocolica posterior anisoperist.

7. III. Nach afebrilem Verlauf geheilt entlassen.

Januar 1906 Brief. Fühlt sich so gesund „als ob er gar nie krank gewesen wäre". Gewichtzunahme $10 \mathrm{~kg}$.

Fall 17. J. N., 23 J., Schneider. Aufgenommen 20. II. 1905. Rechtsseitiger paralytischer Spitzfu@, weswegen Pat. im Alter von 9 Jahren operiert wurde. Seitdem PlattfuBstellung rechts. Seit 10 Jahren chronische Osteomyelitis der 1. Tibia. Februar 1904. Tentamen suicidii mit 1/2 Glas roher Lysollösung. Nach Ablauf der akuten Erscheinungen Schluckbeschwerden, Brechreiz, Magenkrämpfe, Gefühl von Völle im Epigastrium.

Status praesens: Dilatation des Magens bis 3 Finger unter den Nabel, undeutliche Resistenz rechts vom Nabel. Magenplätschern. Ösophagus für Bougie Nr. 20 passierbar.

Operation am 23. II. 1907. Streifige Narben am Pylorus, die denselben bis auf Kleinfingerdicke stenosieren. Gastroenterostomia retroc. post. anisoperist. Starkes postnarkotisches Delirium bis 25. II. 1905.

13. III. 1905. Geheilt entlassen.

Februar 1906. Wegen Osteomyelitis des 1. Unterschenkels neuerlich 
aufgenommen. Subjektiv keine wesentliche Besserung des Magenleidens, objektiv kein pathol. Befund.

Fall 18. K. P., 35 J., Brauereibediensteter. Aufgenommen 7. III. 1905. Seit 20 Jahren starker Potator. Jetzt regelmäBig 10 Liter Bier täglich.

Seit 10 Monaten schlechter Appetit, bitteres AufstoBen, Gefühl eines Fremdkörpers in der Magengegend, Schmerzen rechts vom Nabel, Stuhl angehalten, von teerschwarzer Farbe.

Herbst 1904 wegen Cirrhosis hepatis in Spitalspflege. Abmagerung.

Status praesens: Leberdämpfung verkleinert. Magen druckempfindlich. Kapazität $1200 \mathrm{ccm}$. $\mathrm{HCl}+$, Milchsãure -.

Operation 22. III. 1905. An der Vorderfläche des Magens in der Nähe des Pylorus eine guldengroße strahlige, den Pylorus stenosierende Narbe. Gastroenterostomie retroc. post. anisop.

11. IV. 1905. Geheilt entlassen.

16. I. 1906. Keine Magenschmerzen, aber Obstipation und schlechte Verdauung. Besserung. (Potator.) Geringe Gewichtszunahme.

Fall 19. H. M., 42 J. Aufgenommen 17. III. 1905. Seit 10 Jahren magenleidend. Langsam zunehmende Verschlechterung trotz wiederholter ärztlicher und anderer Behandlung (Pfefferkörnerkur), besonders in den letzten Wochen. Immer heftiger werdendes Erbrechen in den letzten 8. Tagen. Schwarzbraun gefärbt.

Status: In der Magengegend, rechts von der Mittellinie, eine leichte, etwas empfindliche Vorwölbung; lautes Magenplätschern. $\mathrm{HCl}+$, Milchsäure -. Gesamtacidität $16 \%$.

Operation 27. III. Zahlreiche membranöse Verwachsungen zwischen Pylorus Duodenum und Leber. Stenosierender Ulcustumor am Pylorus kaum für einen Finger durchgängig. Gastroenterostomia retrocolica anisoperistaltica.

11. IV. 1905. Geheilt entlassen.

Januar 1906. Keine Beschwerden, gutes Wohlbefinden, $10-11 \mathrm{~kg}$ Gewichtszunahme. Vollkommene Heilung.

Fall 20. H. J., 39 J., Arbeiter. Aufgenommen 21. IV. 1905, zutransferiert 13. V. 1905. Seit 7 Jahren magenleidend; vor 3 Jahren Häma. temesis. Wiederholte Spitalspflege ohne Erfolg. Starker Potator.

Status: Außer Druckempfindlichkeit des Abdomens nichts nachweisbar.

Operation 18. V. 1905: Magen dilatiert, seine Wandung verdickt. Pylorus für die Fingerkuppe kaum einlegbar, verengt. Gastroenterostomia retrocol. posterior anisoperist.

18. VI. 1905. Nach reaktionslosem Verlauf geheilt entlassen.

Januar 1906. Briefliche Anfrage bleibt unbeantwortet.

Fall 21. T. I., 31 J., Hilfsarbeiter. Aufgenommen 16. V. 1905. Vor 6 Jahren das erste Mal heftige Magenschmerzen. Bei Bauchlage besserten sie sich, dauerten aber so lange bis Erbrechen eintrat. Dann schmerzfrei bis zur nächsten Nabrungsaufnahme. Derartige Anfälle daverten immer einige Tage, um dann von selbst abzuklingen und einer Zeit völligen Wohlbefindens zu weichen. Seit Dezember 1904 kaffeesatzartiges Erbrechen. März 1905 frisches Blut erbrochen. Wiederbolte interne Behandlung resultatlos. 
Status: Abdomen keine Resistenz. Magen dilatiert. $\mathrm{HCl}+$, Milchsäure -

Operation 19. V. 1905: Pylorus mit dem Pankreas verwachsen. Großes callöses penetrierendes Magengeschwür. Pylorus stenosiert. Strahlige Narben. Magendilatation. Gastroenterostomia retroc. post. anisoperist.

30. V. 1905. Seit der Operation kein Erbrechen. Geheilt entlassen.

17. I. 1906. Vollständiges Wohlbefinden. Kein Erbrechen seit 1/2 Jahr.

Fall 22. K. Sch., 48 J., Bauer. Aufgenommen 23. V. 1905. Seit 20 Jahren magenleidend, Sodbrennen und Erbrechen kaffeesatzartiger Massen. Anfangs März 1905 hörte das Erbrechen auf, dagegen heftige Schmerzen und Stüble von teerschwarzer Farbe.

Status: Epigastrium stark druckempfindlich, kein Tumor, Magenplätschern. $\mathrm{HCl}+$, Milchsäure -

Operation 2. VI. 1905: Am Pylorus eine strahlige Narbe mit fibrinösen Auflagerungen, Pylorus verengt, Hyperplastische Lymphdrüsen. Gastroenterostomia retrocolica posterior anisoperist.

15. VI. 1905. Nach afebrilem Verlauf geheilt entlassen. $48 \mathrm{~kg}$.

Januar 1906. Vollständiges Wohlbefinden. Keinerlei Verdauungsbeschwerden. Gewicht gegenwärtig $70 \mathrm{~kg}$ (gegen 48 beim Verlassen des Spitals).

Fall 23. A. H., 42 J. Aufgenommen 30. V. 1905. Vor einem Jahr die ersten Magenbeschwerden. Im Oktober 1904 heftiger werdend mit Erbrechen seit Februar.

Status: Magen dilatiert. $\mathrm{HCl}+$, Milchsäure - Blut.

Operation 2. VI. 1905: Am Pylorus melirere strahlige Narben. Pylorus mit dem Pankreaskopf verwachsen, kleinapfelgroBer Tumor, Magenwandung hypertrophisch. Gastroenterostomia retrocolica posterior anisoperistalt.

15. VI. Geheilt entlassen.

11. I. 1906. Antwort auf briefliche Anfrage: Vollständiges Wohlbefinden. Gewichtszunahme $18 \mathrm{~kg}$ in 6 Monaten.

Fall 24. G. S., 27 J., Arbeiter. Aufgenommen 10. VI. 1905. Seit 2 Jahren leidet Patient an heftigen Schmerzen im Kreuz, die aber zeitweilig nachlassen.

Am 15. XII. 1904 fiel ihm eine schwere Eisenplatte gegen den Bauch. Seit der Zeit heftige Magenschmerzen, die besonders nach dem Essen auftraten; bitteres Aufstoßen, Blähungsgefühl, Brechreiz, Bei linker Seitenlage geringer. Stuhl ofters blutig. Spitalbehandlung erfolglos. Abmagerung um $18 \mathrm{~kg}$.

Status praesens: Dilatatio ventriculi. Magenplätschern. $\mathrm{HCl}+$, Milchsäure - .

Operation 13. VI. 1905: Zarte Narbenstränge vom Pylorus $6 \mathrm{~cm}$ entfernt, die dem Magen eine leichte Sanduhrform verleihen. Verwachsungen mit der obersten geknickten Jejunumschlinge. Gastroenterostomia retroc. post. anisoperist.

29. VI. 1905. Geheilt entlassen.

15. IX. 1905. Pat sieht sehr gut aus. Gewicht um $13 \frac{1}{2} \mathrm{~kg}$ mehr. 

bücken.

Dezember 1905. Pat. hat heftige Kreuzschmerzen, kann sich nicht

Januar 1906. Bei vollständigem Wohlbefinden seitens des Magens leidet Pat. an einer Wirbelkaries.

Fall 25. I. G., 32 J., Beamter. Aufgenommen 20. VII. 1905. Im Dezember 1903 plötzlich Hämatemesis, seit damals Schmerzen im Epigastrium, unabhängig von der Nahrungsaufnahme. In der Zeit vom Februar bis Juni $190510 \mathrm{~kg}$ Gewichtsverlust.

Status praesens: Magen dilatiert. $\mathrm{HCl}+$. Milchsäure -. Massenhaft Sarcine.

Operation 22. VII. 1905: Reichliche perigastritische Adhäsionen, Durchtrennung derselben. Magen dilatiert. Am Pylorus nußgroBer, weicher, entzündlicher Tumor; hochgradige Pylorusstenose. Gastroeniterostomia retrocolica posterior anisoperist. Starkes Erbrechen, Puls schlecht, Kochsalz, Kampfer.

24. VII. Exitus.

Obduktion: Längliches ovales Ulcus pepticum an der vorderen Wand des Duodenums knapp unter dem Pylorus. Pericholecystitis. Stenosis pylori, ectasia ventriculi. Chronischer Magenkatarrh. Atrophie der Magenwand, der Leber und des Herzmuskels, der Niere und der Milz. Chronische Tuberkulose beider Lungen, Kolloidstruma. Lobulärpneumonie beiderseits.

Fall 26. G. G., 39 J., Postbeamter. Aufgenommen 20. VII. 1905. Seit dem 21. Lebensjahr bestehen Schmerzen nach dem Essen, Brechreiz und Erbrechen, Hämatemesis wiederholt. Nervöse Symptome allgemeiner Natur.

Status: Magen dilatiert.

Operation 25. VII. 1905: Magen hypertrophisch. Am Pylorus eine zehnhellerstuckgroße strahlige Narbe. Gastroenterostomia retrocolica post. anisoperist.

27. VII. Unter Erbrechen und allgemeiner Schwäche Exitus.

Obduktion: Maximale Füllung und Dehnung des Magens, Kompression des abführenden Schenkels durch Incarceration in den Mesocolonschlitz, beginnende Aspirationspneumonie, trübe Schwellung des Herzmuskels und der Leber, fettige Degeneration der Niere.

Fall 27. I. A., 47 J., Buchhalter. Aufgenommen 5. VIII. 1905. Im Jahre 1900 wurde am Patient wegen Cholelithiasis und Stenose die Cholecystenteroanastomose ausgeführt. Seit April 1905 häufiges Erbrechen, nie bluthaltig. Abmagerung. Schmerzen.

Status: Abdomen schlaff. Magengegend gebläht. Enorme Magendilatation. Magenplätschern.

Operation 16. VIII. 1905: Magen enorm dilatiert. Große Kurvatur raicht bis zur Symphyse. Pylorus frei; unterhalb desselben Stränge und Verwachsungen, die den Pylorusausgang verengern. Gastroenterostomia retrocolica posterior. Anastomose für $5 \frac{1}{2} \mathrm{~cm}$ durchgängig. Erbrechen nach der Operation, allgemeine zunehmende Schwäche.

19. VIII. 1905. Exitus.

Obduktion: Akutes Lungenödem, eitrige Bronchitis. Enorme Magenektasie. Stenosis duodeni durch eine schrumpfende Narbe in der Höhe 
Zur Statistik der Gastroenterostomien bei benignen Magenerkrankungen. 537

der Papille nach Ulcus duodeni mit Stenosis des Duct. choledochus und pancreaticus. Gastroenterostomia facta Cholecystenteroanastomose. Ductus choledochus stenosiert.

Fall 28. A. St., 26 J. Aufgenommen 11. IX. 1905. Seit 4 Jahren magenleidend mit einer Pause von 2 Jahren. Seit 2 Monaten vermehrte Beschwerden mit fast täglichem Erbrechen; nie Blut.

Status: Untere Magengrenze 2 Querfinger unterhalb des Nabels. Magenplätschern. Kapazität 2300. $\mathrm{HCl}+$, Milchsäure - .

Operation 12. IX. 1905: Multiple perigastritische Verwachsungen mit dem Colon und dem Jejunum. Am Pylorus kronenstückgroßes callöses Ulcus. Pylorus stark verengt. Gastroenterostomia retrocolica posterior anisoperistaltica.

25. IX. 1905. Geheilt entlassen.

Brief im Januar 1906. Pat. fühlt sich ganz gesund. $6 \mathrm{~kg}$ Gewichtszunahme.

Fall 29. F. R., 31 J., Maurer. Aufgenommen 2. X. 1905. Vor 4 Monaten Magendrücken, saures AufstoBen, Magenkrämpfe. Stühle hart und schwarz, nie Erbrechen. Im 11. Lebensjahr wurde Patient von einem Wagen überfahren (Räder über den Magen).

Status: Große Kurvatur in Nabelhöhe. Magenplätschern. Kapazität 1250. $\mathrm{HCl}+$, Milchsäure -. Körpergewicht $451 / 2 \mathrm{~kg}$ gegen $75 \mathrm{~kg}$ vor 4 Monaten.

Operation 12. X. 1905: An der vorderen und hinteren Wand der Pars pylorica je eine strahlige Narbe. Jejunum an den Magen adhärent. Gastroenterostomia retrocolica posterior anisoperistaltica.

9. XI. Nach afebrilem Verlauf geheilt entlassen.

11. I. 1906. Antwort auf briefliche Anfrage: Relatives Wohlbefinden, Nahteiterung. Gewichtszunahme $5 \mathrm{~kg}$.

Juli 1906. Noch immer Nahteiterung, keine Schmerzen. Gewichtszuuahme im ganzen $8 \mathrm{~kg}$.

Fall 30. Z. K., 49 J., Stockbieger. Aufgenommen Oktober 1905. Ein Bruder an einem Magenleiden gestorben. Leiden dauert seit 31 Jahren. Aufstoßen, häufiges Erbrechen und Magenschmerzen. Abmagerung (von 69 auf $62 \mathrm{~kg}$ ). Seit Mai Erbrechen schwarzer Massen oder Klumpen von Blut. Stuhl träge. Patient ist Stockbieger. Bei seinem Beruf drückt er sich immer gegen den Bauch.

Status: Magen vergrößert, Magenplätschern. Kapazität $2250 \mathrm{ccm}$. $\mathrm{HCl}+$, Milchsäure -.

Operation 7. X. 1905: Magen dilatiert, Pylorus fixiert; daselbst eine weiche Infiltration, kein Tumor. Gastroenterostomia retrocolica posterior anisoperistaltica.

28. X. 1905. Nach reaktionslosem Verlauf geheilt entlassen.

Januar 1906. Vollständige Heilung, sehr zufrieden. Gewichtszunahme von $56^{1 / 2}$ auf $67 \mathrm{~kg}$.

Juli 1906. Patient leidet an Blähungen, hatte dreimal Erbrechen, fühlt sich aber sonst ganz wohl. Körpergewicht gegenwärtig $72 \mathrm{~kg}$ (Gesamtzunahme zirka $16 \mathrm{~kg}$ ). 
Fall 31. L. K., 40 J., Tagelöhner. Aufgenommen Oktober 1905. Seit 2 Jahren magenleidend, Erbrechen nach dem Essen, Abmagerung. Nie Hämatemesis.

Status: GroBe Kurvatur 2 Querfinger unter den Nabel reichend, Magensteifung, kein Tumor; $\mathrm{HCl}+$, Milchsäure -. Gewicht $54 \mathrm{~kg}$.

Operation 10. X. 1905: Am Pylorus sternförmige Narbe. Stenose des Pylorus für den Kleinfinger durchgängig. Gastroenterostomia retrocolica posterior anisoperist.

Nach afebrilem Verlauf mit Gewicht von $601 / 2 \mathrm{~kg}$ geheilt entlassen.

13. I. 1906 Brief. Befinden ausgezeichnet, Körpergewicht $65 \mathrm{~kg}$.

Juli 1906. Befinden ausgezeichnet. Körpergewicht $69 \mathrm{~kg}$.

Fall 32. S. P., 45 J. Aufgenommen 4. X. 1905. Seit 12 Jahren magenleidend. Beschwerden meist nach dem Essen, Üblichkeiten, saures AufstoBen. Krampfartige Magenschmerzen und Erbrechen seit 6 Jahren, seit 3 Jahren auch Abmagerung. Im Erbrochenen Reste von Speisen, die Pat. 2-3 Tage vorher genossen hatte.

Status: Magen dilatiert, keine Resistenz. $\mathrm{HCl}+$, Milchsäure - .

13. X. 1905 Operation. Magen dilatiert, an der Pars' pylorica ein kleiner, nußgroßer, entzündlicher, beweglicher Tumor. Narben in der Serosa daselbst. Gastroenterostomia retrocolica posterior anisoperist.

9. XI. 1905. Geheilt entlassen.

Januar 1906. Gar keine Beschwerden seit der Operation. Gewichtszunahme $20 \mathrm{~kg}$.

JuIi 1906. Vollkommen gesund. Gesamtgewichtszunahme $23 \mathrm{~kg}$.

Frauen (24 Fälle).

Fall 33. Sch. M., 19 J., Magd. Aufgenommen 22. X. $1903 . \quad$ Im Alter von 12 Jahren blieb der Pat. eine harte Brotrinde im Ösophagus stecken, die erst nach langem Bemühen heruntergewürgt wurde. Einen Monat später trat Hämatemesis ein. Vor 2 Jahren, ohne daß Beschwerden vorausgegangen wären, neuerliche Hämatemesis. Im Oktober 1902 Magendrücken und Erbrechen schwarzer Massen 1-2mal täglich. Stuhl teerschwarz. Juni 1903 hellrotes Blut im Stuhl. Kopfschmerzen, Schwindel. Interne Behandlung resultatlos.

Status praesens: Druckpunkt im Hypochondrium, drei Finger unter dem Proc. xyphoides. Heftiger Ileocöcalschmerz.

30. X. 1903 Operation. Narbige Pylorusstenose. Gastroenterostomia retroc. post. isoperist. Appendektomie.

Januar 1906. Nach der Operation ein Jahr lang Schmerzen. $1 \mathrm{~kg}$ Gewichtsverlust. Jetzt wieder $3 \mathrm{~kg}$ zugenommen. Etwas "Magenbrennen“, sonst Wohlbefinden.

Fall 34. F. Sch, 31 J., Marquersgattin. Aufgenommen 16. II. 1904. Vor 5 Jahren erste Magenbeschwerden mit Schmerzen nach dem Essen, Sodbrennen und fast täglichem Erbrechen. Ambul. Behandlung, Besserung, bald neuerliche Beschwerden, wiederholte Spitalspflege mit stets nur vorübergehender Besserung. Nie Blut erbrochen.

Status: Bauchdecken schlaft. Bei stoßweiser Palpation Magenplätschern. Kein Tumor. Kapazität $1700 . \mathrm{HCl}+$, Milchsäure -. 
Zur Statistik der Gastroenterostomien bei benignen Magenerkrankungen. 539

Operation am 20. II. 1904. Pylorus rings durch Adhäsionen mit der Porta hepatis verklebt, an der hinteren Pyloruswand eine kronenstückgroße, strahlige Ulcusnarbe. Vergrößerte Drüsen. Gastorenterostomia retroc. post. sec. v. Hacker.

7. III. 1904. Geheilt entlassen.

Histologisch kein Carcinom.

Brief im Januar 1906: Bis zum Juni 1905 vollständiges Wohlbefinden. Damals plötzliches Bluterbrechen und durch 14 Tage Mattigkeit. Dann wieder vollständiges Wohlbefinden bis jetzt, Gewichtszunahme $13 \mathrm{~kg}$.

Fall 35. St. B., 49 J. Aufgenommen 19. II. 1904. Mit 24 Jahren häufiges Erbrechen, nie blutig, durch 4 Jahre. Dann 6 Jahre Wohlbefinden. Dann wieder dieselben Beschwerden. Ohne Zusammenhang mit Nahrungsaufnalme, vielmehr sollen sensible Reize, wie Zwiebel und Knoblauchgeruch, den Anla $B$ zum Erbrechen gegeben haben.

17. IV. 1899 wegen Myom vaginale Hysterektomie. Seit Oktober 1901 Verschlimmerung der Magenbeschwerden. Abmagerung. Seit 5 Monaten wird nur Milch vertragen. Interne Behandlung ohne Erfolg.

Status: Abdomen druckempfindlich. Kein Tumor. Milchsäure --, $\mathrm{HCl}+$ Kapazität 2600.

26. II. 1904 Operation. Ulcus an der kleinen Kurvatur. Gastroterostomia retrocolica posterior.

7. III. 1904. Geheilt entlassen.

17. I. 1906 stellt sich Patientin vor. Klagt über häufiges AufstoBen, aber nie Erbrechen, dagegen häufige Blutbeimengungen im Stuhl. Zeitweise Besserung. Obj. sieht die Frau blühend aus. (Ovarie, kein Rachenreflex, kein Comealreflex.) Vorwölbung der Layarotomienarbe.

Fall 36. T. K., 25 J., Bäuerin. Aufgenommen 6. V. 1904. Als junges Mädchen Chlorose. Seit 6 Jahren Magenbeschwerden; interne Behandlung, August 1903 wesentliche Verschlimmerung. Interne Behandlung erfolglos, ab Oktober 1903 schwarze Stühle.

Status: Im 1. Epigastrium etwas empfindliche Resistenz.

Operation 14. V. 1904. Ulcus an der kleinen Kurvatur mit der vorderen Bauchwand verwacbsen. Gastroenterostomia retrocolica posterior. Reaktionsloser Verlauf.

3. VI. 1904. Geheilt mit 341/4 kg Gewicht entlassen.

10. I. 1906. Briefliche Anfrage: Angeblich nervöse Beschwerden (Neurasthenie?) Bedeutende Besserung. Gewichtszunahme $9 \mathrm{~kg}$. Verträgt alle Speisen.

Fall 37. 0. v. G., 39 J., Private. Aufgenommen 21. VI. 1904. In ihrer Jugend litt die Patientin an Chlorose. Seit ihrem 17. Lebensjahre ist die Patientin magenleidend, häufiges Erbrechen, Appetitlosigkeit, Stuhlverstopfung. Vor 8 Jahren verspürte sie plötzlich während des Essens einen bohrenden Schmerz im Magen, der seitdem fortbestand. Pat. vertrug nur Milch und Milchspeisen. Abmagerung um $18 \mathrm{~kg}$ in 4 Jahren. 30. IV. 1900 wurde sie operiert (Gastrolysis), doch war die erzielte Besserung nur von kurzer Dauer. 4 Wochen Karlsbader Kur besserten den Zustand, doch sah sich die Patientin bald darauf gezwungen, eine neuerliche Karlsbader Kur zu gebrauchen, ohne Erfolg. Daher Okitober 
1903 neuerliche Operation (Pyloroplastik). Auch nach dieser Operation keine Besserung. In der letzten Zeit neuerdings wiederholtes Erbrechen, bohrende Schmerzen, Abnahme des Körpergewichts.

Status praesens: Rechts vom Nabel eine unscharf begrenzte Resistenz. Ein strangtörmiger Tumor zieht von hier zum linken Rippenbogen. Magenplätschern.

Operation 23. VI. 1903. Derartige flächenhafte Verwachsungen zwischen Bauchwand, Netz, Magen und Leber, daß der Pylorus gar nicht zu Gesicht kommt. Gastroent. retrocol. post. anisop.

3. VII. 1903. Nach reaktionslosem Verlauf geheilt entlassen. Bald darauf stellten sich wieder "Darmkrämpfe" ein, besonders kurz vor der Stuhlt entleerung. Stuhl angehalten, oft tagelang ausbleibend. Dabei immer AufstoBen.

Januar 1906. Neuerliche Spitalaufnahme, Darmkrämpfe konstant. Erbrechen fehlend. Bei Bettruhe etwas Besserung. Massage der Bauchdecken. Lagerungstherapie bringt etwas Erleichterung, doch ist im Juli 1906 der Zustand verändert. Nur das Erbrechen hat vollständig aufgehört.

Röntgenaufnahme Juni 1906 zeigt den durch Wismut dunkel gefärbten Magen und von dessen unterer Begrenzung einen von rechts nach links ziehenden dunklen, etwa fingerbreiten Streifen, der sich allmählich verliert (Wismut gefüllter abführender Schenkel).

Fall 38. A. P., 12 J. Aufgenommen 23. VI. 1904. Vor 4 Jahren Magenbeschwerden, besonders heftig nach der Nahrungsaufnahme. Nie Erbrechen. Vor 4 Jahren plötzlich Bluterbrechen.

Status: Magen etwas erweitert. Kein Tumor.

Operation 28. VI. 1904. Magen an einer Stelle der kleinen Kurvatur mit der Bauchwand verlötet, leichte Perigastritis. Gastroenterostomia retrocolica post.

14. VII. 1904. Geheilt entlassen.

Januar 1906. Brief liche Anfrage. Patientin fühlt sich seit der Operation bedeutend schlechter, leidet an Krämpfen und Aufstoßen; keine Gewichtszunahme. ${ }^{1}$ )

Fall 39. A. S., 59 J. Aufgenommen 20. XI. 1904. Vor 7 Jahren wurde die Frau durch einen rollenden Baumstamm beim Abladen von Bäumen in die Magengegend getroffen, Ohnmacht. Einige Tage darauf traten Schmerzen in der Umgebung des Nabels auf, Erbrechen nach jeder Mahlzeit, durch ein ganzes Jahr. Dann vorübergehende Besserung insofern, als die Schmerzen und das Erbrechen nur alle 2-3 Tage auftraten bis August 1904. Plötzlich heftige Hämatemesis (ein Lavoir voll). Dann Blutcoagula erbrochen. Tags darauf neuerliche Hämatemesis.

S tatu s: Abdomen vorgewölbt, reichliche Plätschergeräusche. Mageninhalt $\mathrm{HCl}$ - , Milchsäure - Kein Tumor nachweisbar.

Operation 30. XI. 1904. Mächtig dilatierte Venen des Netzes (bis zur Bleistiftdicke). Verwachsungen desselben mit dem Magen, der hinteren Magenwand mit dem Pankreaskopf. Daselbst ein guldenstückgroBes callöses Ulcus. Gastroenterostomia retrocolica post.

1) Im Frühjahr 1906 bekam Pat. ihre ersten Menses, seit dieser Zeit keine Beschwerden, bedeutende Gewichtszunahme. (Nachricht Juni 1907). 
Zur Statistik der Gastroenterostomien bei benignen Magenerkrankungen. $\mathbf{5 4 1}$

9. XII. Bronchitis. 11. XII. Pneumonie. 19. XII. Zunehmende Schwäche. 20. XII. Exitus.

Obduktion (Prof. Ghon). Großes, chronisches, rundes Magengeschwür an der hinteren Magenwand mit Verlötung des Pankreas und Schrumpfung der Plica duodenojejunalis. Thrombose der Vena portae und ihrer intrahepatischen Äste, der linken Nierenvene und der Vena cava inferior und der rechten Vena iliaca. Gastroenterostomia retrocolica post. ante dies XX facta. Adhäsionen des großen Netzes in der linken Inguinalgegend und an das Colon transverum und mit der zur Anastomose verwendeten Jejunumschlinge. Lobulärpneumonische Herde beiderseits, kleiner gangränöser Herd rechts, Pleuritis, Degeneratio adiposa Myocardii, Atheromatosis valvul, aortae.

Fall 40. T. H., 40 J., Private. Aufgenommen 27. XI. 1904. Vor 13 Jahren hatte Patientin die ersten Schmerzen, die von ihr bald in der Mitte des Bauches, bald in der Flankengegend lokalisiert wurden und meist nach Genuß sauer Speisen empfunden wurden. Später trat auch noch Erbrechen dazu, nie blutig, schwarz oder kaffeesatzartig. Die anfallsweisen von Erbrechen gefolgten Schmerzen traten in unregelmäßigen Zeitintervallen auf.

Status praesens: Abdomen vorgetrieben. Magen reicht bis zwei Querfinger unter den Nabel, rechts vom Nabel eine nicht empfindliche Resistenz. Kein Plätschern.

3. XII. 1904 Operation. Strangförmige Adhäsionen zwischen Magen, Gallenblase und dem Colon transversum. Colon transversum gebläht. Magen dilatiert, am Pylorus eine ringförmige, für die Fingerkuppe einlegbare Stenose. Gastroenterostomia retrocol. post. anisoperist.

Verlauf durch Pneumonie kompliziert.

17. XII. Geheilt entlassen.

Schon auf der Heimfahrt von der Klinik wurde die Frau von neuerlichen kolikartigen Schmerzen befallen, die von Erbrechen gefolgt waren. Außerdem bestanden heftige Diarrhöen.

2. I. 1905. Neuerliche Spitalaufnahme. Schmerzen in der Umgebung des Nabels, Darmsteifung.

12. I. 1905. Nach Milchdiät gebessert entlassen.

Da sich die Beschwerden bis September 1905 nicht besserten und der Pat. bei einem Spitalaufenthalt in Budapest eine neuerliche Operation vorgeschlagen wurde, suchte Pat. neuerdings die Klinik auf.

Status: Empfindlichkeit im Mesogastrium, ab und zu Darmsteifung.

9. IX. 1905 Operation. Nach Eröffnung des Abdomens $1 \mathrm{~m}$ vom Pylorus eine Dünndarmstenose, der in kurzen Abständen noch 17 andere folgen, die letzte nahe der Ileocöcalklappe. Die gröBte Distanz zwischen zwei Stenosen beträgt etwa $50 \mathrm{~cm}$. Der orale Anteil dieser Partie wird mit dem Dünndarm über der 1. Stenose anastomosiert, das aborale mit dem Colon, so daB im ganzen ca. $11 / 2 \mathrm{~m}$ Dünndarm der Verdauung verbleiben.

Die G. E. war suffizient.

29. IX. 1905. Geheilt entlassen.

Am 7. X. kommt Pat. mit neuerlichen Beschwerden. Ganzes Abdomen empfindlich. Erbrechen von gelbem, zähem Schleim. Magenausspülungen, Nährklysmen. 
13. X. Schmerzen ungemein heftig.

22. X. Auf Wunsch entlassen.

24. XI 1905. Auf einer internen Station unter Erscheinungen der Dünndarmstenose gestorben.

Sektion ergab allgemeine Atrophie der Organe. 17 Darm und Pylorusstenose auf Basis tuberkulöser Strikturen. ${ }^{\text {) }}$

F'all 41. R. F., 40 J., Lehrerin, aufgenommen 6. XII. 1904. Vor 4 Jahren Druckschmerzhaftigkeit des Abdomens. Interne Behandlung wegen Ulcus. Dann beschwerdefrei bis vor 3 Monaten. Damals Brechreiz, Schmerzen, andauernd bis Dezember 1904. Nie Erbrechen.

Status: AuBer lokaler Druckschmerzhaftigkeit, negativer Befund.

13. XII. 1904. Operation. Verwachsungen zwischen Gallenblase und Magen. Der Pylorus durch Adhäsionen geknickt. Pylorus stenosiert, knapp für einen Bleistift durchgängig. Durchtrennung der Adhäsionen. Gastroenterostomia retrocolica post. anisoperist.

6. I. 1905 . Geheilt entlassen.

Januar 1906. Angeblich leichte Verdaungsbeschwerden, wesentliche Besserung. Gewichtszunahme $4 \mathrm{~kg}$.

Fall 42. T. W., 28 J., aufgenommen 11. I. 1905. Seit 7 Jahren an Magenschmerzen und Übelkeiten leidend. Erbrechen erst seit Frühjahr 1904. Keine Hämatemesis.

Status praesens: Magengegend vorgewölbt. Magenplätschern. Große Kurvatur 1 Querfinger unterm Nabel; Druckempfindlichkeit; kein Tumor. Kapazität 3500, Gesamtacidität 2,9\% $\%$, HCl +, Milchsäure-.

operation 17. I. 1905. Stark dilatierter Magen mit verdickten Wandungen. Ulcusnarbe am Pylorus mit bedeutender Verengerung desselben. Gastroenterostomia retrocolica posterior anisoperist.

Nach der Operation am 24. I. 1905 wegen Lungentuberkulose auf die II. mediz. Klinik transferiert.

Januar 1906. Patientin ist verschollen.

Fall 43. E. H., 44 J., Private, aufgenommen 18. I. 1905. Transferiert 3. II. 1905. Vor 6 Jahren entstanden nach einer Gravidität typische Ulcusbeschwerden, die allmählich an Intensität und Häufigkeit zunahmen. Oft Erbrechen, nie mit Blut gemengt, dagegen reichlich teerschwarze Stühle.

Status: Magen dilatiert, druckempfindlich, kein Tumor, Magenplätschern.

Operation: 10. II. 1905. An der kleinen Kurvatur in der Nähe des Pylorus ein kreuzergroßes callöses Ulcus. Magen dilatiert. Keine Drüsen. Gastroenterostomia retrocolica posterior anisoperist.

28. II. 1905. Nach afebrilem Verlauf geheilt entlassen.

1) Payr hat vor nicht langer Zeit 50 Fälle von gleichzeitiger oder bald nach einander sich entwickelnder Kombination von Magen- und Darmstenose aus der Literatur zusammengestellt und die Kasuistik um 8 neue Fälle bereichert. Die Ursachen können in der Magenaffektion selbst oder in einer Allgemeinerkrankung liegen. Der hier erwähnte Fall reiht sich den Payrschen Fällen an. 
Zur Statistik der Gastroenterostomien bei benignen Magenerkrankungen. 543

Am 19. I. 1906 ist Pat. unter neuerlich einsetzenden Magenbeschwerden an einer internen Station gestorben.

Obduktion: Medulläres, diffus infiltrierendes Magencarcinom auf Basis einer Ulcusnarbe mit mäBiger Stenosierung des Pylorus, Lebermetastasen, Embolie der Pulmonalarterie.

Fall 44. T. Sz., 19 J., Magd, aufgenommen März 1905. Im Februar 1904 an Ikterus gelitten, Schmerzen in der Lebergegend seit jener Zeit fortbestehend, seit Januar 1905 auch Erbrechen nach größeren Mahlzeiten, einigemal auch Hämatemesis, dabei teerfarbene Stähle.

Status: 2 Querfinger oberhalb des Nabels, 1 Querfinger rechts von der Mittellinie eine walnuBgroße Resistenz, schmerzhaft, druckempfindlich.

Operation: 21. III. 1905. Der Pylorus durch Narbenschrumpfung so stark stenosiert, daß er kaum für die Fingerkuppe einlegbar ist. Neben dem Pylorus an der kleinen Kurvatur eine kleine Narbe.

Gastroenterostomia retrocolica post. anisoperist.

Am 15. IV. nach geringen Schmerzen gegen Ende der Rekonvaleszenz geheilt entlassen.

Brief im Januar 1906: Bis jetzt besteht AufstoBen und Erbrechen, Gewichtszunahme unbekannt, leichte Besserung.

Fall 45. J. B., 29 J., aufgenommen 20. III. 1905. Vor 3 Jahren Appendixanfall; seitdem Obstipation. Gefühl von Völle im Magen, Appetit gut. Nie Erbrechen.

Status: Druckempfindlichkeit in der Ileocöcalgegend. Magenerweiterung. Plätschern. Unverdaute Speisereste im Mageninhalt.

Operation: 22. III. 1905. Magen dilatiert, kein Ulcus, keine Narbe, keine Pylorusstenose, jedoch durch einige Adhäsionen an der Gallenblase fixiert. Appendix ebenfalls durch Adhäsionen an das Peritoneum fixiert.

Appendektomie. Gastroenterostomia retroc. post. anisoperist.

9. IV. Nach afebrilem Verlauf geheilt entlassen.

18. I. 1906. Vorstellung: Völliges Wohlbefinden. Gewichtszunahme $3 \mathrm{~kg}$.

Fall 46. M. R., 31 J., Schuhmachersgattin, aufgenommen 2. IV. 1905. Seit 5 Jahren meist nächtliche Magenschmerzen, häufiges Erbrechen nach dem Essen, nie Blut enthaltend. Abmagerung.

Status: Abdomen weich. Kein Tumor, Magen bis 3 Querfinger unter den Nabel reichend, Plätschern.

Operation am 4. IV. 1905. Magen zeigt eine leichte Sanduhrform. An der kleinen Kurvatur eine kleine derbe Narbe, eine zweite am Pylorus, die Pyloruspassage stark verengend. Im Mesenterium geschwollene Lymphdrüsen (histolog. kein Carc.). Gastroenterostomia retrocolica poster. anisoperist.

18. IV. Geheilt entlassen.

Brief im Februar 1906: Keine subjektiven Beschwerden, vollständiges Wohlbetinden, $12 \mathrm{~kg}$ Gewichtszunahme.

Fall 47. M. H., 41 J., Schuhmachersgattin, aufgenommen 17. V. 1905. Vor 2 Jahren Magenbeschwerden. Erbrechen, nie Blut enthaltend. Nach interner Medikation Besserung des Zustandes bis Weihnachten 1904. Seitdem neuerliche Ulcusbeschwerden.

Status: Magen bis handbreit unter den Nabel reichend. In Nabel- 
höhe ein etwa hühnereigroßer Tumor zu tasten. Kapazität $2500 \mathrm{ccm} . \mathrm{HCl}+$, Milchsäure +, Körpergewicht $51 \mathrm{~kg}$.

Operation am 20. V. 1905. Colon gebläht, Magen dilatiert und hypertrophisch, tiefstehend. Am Pylorus starke Verwachsungen, kein Tumor, aber ein Ulcus, das den Pylorus auf Federkieldicke verengt.

Gastroenterostomia retrocolica post. anisoperist.

Nach afebrilem Verlauf am 5. VI. 1905 geheilt entlassen.

20. I. 1906 stellt sich Pat. persönlich vor. Obj. nichts nachweisbar. Kanı alles essen, befindet sich ausgezeichnet, spürt Gewichtszunahme.

Fall 48. A. Ch., 28 J., aufgenommen 27. V. 1905. 3 Partus. Nach dem letzten am 3. Tage krampfartige Magenschmerzen, am 6. Tage Erbrechen. Seit 2 Monaten tägliches, oft wiederholtes Erbrechen, einigemal mit Blut in Form hellroter Streifen gemengt. Patientin enorm abgemagert (von 65 auf $46^{1 / 2} \mathrm{~kg}$ ).

Status: Flache Vorwölbung in der Magengegend, Magensteifung, Plätschern, kein Tumor, Magen 4 Querfinger unter den Nabel reichend. $\mathrm{HCl}+$, Milchsäure -.

30. V. 1905 Operation. Enorm dilatierter Magen mit verdickten Wandungen. Am Pylorus ein walnußgroßer entzündlicher Tumor, den Pylorus fast völlig verengernd.

Gastroenterostomia retrocolica posterior anisoperistalt.

16. VI. 1905. Pat. wird in sehr zufriedenem Zustand entlassen.

2. XI. 1905 stellt sich Pat. vor. Seit 16. VI. 1905 kein Erbrechen. Gewicht $52^{1} / 4 \mathrm{~kg}$.

Brief im Januar 1906: Zeitweise Aufstoßen, kein Erbrechen. Gewichtszunahme $6 \mathrm{~kg}$. Wohlbefinden, wesentliche Besserung.

Mai 1906: Röntgenaufuahme ergibt unklaren Befund. Pat. klagt über Erbrechen besonders in der Frühe, unabhängig von der Nahrungsaufnahme. Sie ist gegenwärtig im 4. Monat gravid. Körpergewicht stationär.

Fall 49. W. M., 21 J., Magd, aufgenommen 2. VI. 1905. Vor 2 bis 3 Monaten Magendrücken. Vor 14 Tagen vermehrte Beschwerden, vor 4 Tagen Hämatemesis, Schmerzen, Schwindelanfälle.

Status: Am Herzen anämische Geräusche. Abdomineller Befund negativ. Ulcusdiät.

Operation am 16. VI. 1905. Strangförmige, schräg über dew Pylorus verlaufende Narbe.

Gastroenterostomia retrocolica posterior anisoperist. Erbrechen bis 26. VI. 1905.

3. VII. 1905 geheilt entlassen.

8. I. 1906. Nachuntersucht: Patientin verträgt alles gut, leidet nur an großer Mattigkeit und Aufstoßen. Abgang von Täniengliedern im Stuhl. Kein Erbrechen. Appetit gut.

Fall 50. K. W., 23 J., aufgenommen 12. VIII. 1905. Seit 3 Jahren Magenbeschwerden von wechselnder Intensität; fast tägliches Erbrechen. Vor 14 Tagen Bluterbrechen durch 4 Tage. Gewichtsverlust in den letzten 3 Jahren $8 \mathrm{~kg}$.

Status: Außer starker Druckempfindlichkeit des Abdomens negativer Befund. 
Zur Statistik der Gastroenterostomien bei benignen Magenerkrankungen. $\mathbf{5 4 5}$

17. VIII. 1905 0peration. Magen dilatiert. Strahlige Narben des Pylorus. Gastroenterostomia retrocolica post. anisoperist.

31. VIII. 1905 geheilt entlassen.

13. I. 1906. Antwort auf Brief: Sehr zufriedener Zustand. Gewichtszunahme $71 / 2 \mathrm{~kg}$.

Juli 1906. Patientin ist seit der Operation vollständig gesund. Gewichtszunahme $12 \mathrm{~kg}$.

Fall 51. A. S., 34 J., Magd, aufgenommen 15. VIII. 1905. Seit Januar 1905 Erbrechen nach jeder Mahlzeit. Seit Mai auch Magenschmerzen. Keine Hämatemesis.

Status: Magen dilatiert, Magenplätschern bis unterhalb des Nabels. $\mathrm{HCl}+$, Milchsäure -

Operation am 22. VIII. 1905. Magen stark dilatiert, nahe der kleinen Kurvatur ein eingezogenes altes Ulcus mit aufgeworfenen Rändern. Adhäsionen an der Leber. Ascites. Gastroenterostomia retrocolica posterior anisoperist.

8. XI. 1905 geheilt entlassen.

Brief im Januar 1906: Patientin fühlt sich vollkommen gesund.

Gewichtszunahme $23 \mathrm{~kg}$.

Gewichtszunahme im Juli $190623 \mathrm{~kg}$. Vollständige Heilung.

Fall 52. R. F., 27 J., Lehrerin, aufgenommen 16. VIII. 1905. Patientin wurde am 19. III. 1904 operiert. Cholecystektomie mit Eröffnung des Ductuscysticus, Entfernung dreier bohnengroßer Steine. Im November 1904 krampfartige Magenschmerzen durch kurze Zeit. März 1905 neuerliche Schmerzen im Abdomen; nie Erbrechen. Stuhl von dunkelbrauner Farbe.

Status: Am Abdomen nichts Besonderes tastbar.

19. VIII. 1905 Operation. Magen am Peritoneum adhärent. Verwachsungen des Magens mit der Leber und dem Colon transversum, die den Pylorus verengern.

Gastroenterostomia retrocolica posterior anisoperistaltica.

3. IX. 1905. Nach reaktionslosem Verlauf geheilt entlassen.

Briefliche Anfrage am 12. I. 1906 beantwortet: Keine Magenkrämpfe mehr. Häufige Hämoptoë und Durchfälle.

Juli 1906. Patientin lat heftige Bauchschmerzen, kein Erbrechen; blutiger Auswurf, Nachtschweiße, blutige Stühle. Gewicht um $4 \mathrm{~kg}$ vermindert.

Fall 53. R. Z., 49 J., Bäuerin, aufgenommen 18. VIII. 1905. Seit 6-7 Wochen mit äußerst heftigen Schmerzen in der Magengegend und Erbrechen krank. Nie Blut im Erbrochenen. Einige Male teerschwarze Stühle.

Status: Rechts vom Nabel tastet man eine in die Leberdämpfung übergehende Vorwölbung, Magen dilatiert. $\mathrm{HCl}-$, Milchsäure +.

23. VIII. 1905 Operation. An der kleinen Kurvatur ein callöses, nicht carcinomatöses Geschwär, perigastritische Verwachsungen. Schnürlappen der Leber.

Gastroenterostomia retrocolica post. anisoperistalt.

7. IX. 1905. Nach afebrilem Verlauf geheilt entlassen.

Deutsche Zeitschrift f. Chirurgie. 88. Bd. 
13. I. 1906. Antwort auf briefl. Anfrage: Stuhlbeschwerden. Brennen im Magen. Kein Erbrechen. Allgemeine Besserung. Gewichtszunahme $11 \mathrm{~kg}$.

Juli 1906. Pat. fühlt sich besser. Gewichtsverlust $4^{1 / 2} \mathrm{~kg}$.

Fall 54. Sch. A., 40 J., Kleinhäuslerin, aufgenommen 30. X. 1905. Vor 20 Jahren litt sie längere Zeit an Magenbeschwerden und erbrach einigemal Blut. Nach 1/2 Jahre spontane Besserung. Seit 3 Jahren neuerdings heftige Schmerzen nach dem Essen, die einige Stunden andauern. Brechreiz und AufstoBen. Nach künstlich hervorgerufenem Erbrechen Erleichterung. Wiederholt schwarzes Erbrechen, einmal auch hellrot. Oktober 1904 letzte Hämatemesis. Seit $1 \frac{1}{2} 2$ Jahren spült sich die Patientin täglich abends den Magen aus, was etwas zur Erleichterung beiträgt. 1903 und 1904 Karlsbader Kur ohne nennenswertes Resultat.

Status: Magenplätschern, scharf umschriebene Druckempfindlichkeit. Kapazität $1000 \mathrm{ccm}$. $\mathrm{HCl}+$, Milchsäure - .

0 peration am 2. XI. 1905. Magen an das Peritoneum parietale angewachsen. Im mittleren Drittel der vorderen Magenwand eine strahlige Narbe, die dem Magen in geringem Grade eine Sanduhrform verleiht. Mehr pyloruswärts ein Tumor, der von der kleinen Kurvatur ausgehend eine fast zirkuläre Stenose verursacht.

Einige bohnengroße Drüsen. Adhäsionen, die das Vorziehen des Magens verhindern.

Gastroenterostomia antecolica anterior mit Enteroanastomose der beiden Schenkel. cinom.

20. XI. geheilt entlassen. Gewicht 57,75 kg. Histologisch kein Car-

11. I. 1906. Keine Beschwerden. Verträgt alles. Völlige Gesundung. Gewichtszunahme $14 \mathrm{~kg}(71)$ in 2 Monaten und 9 Tagen.

Juli 1906. Vollständiges Wohlbefinden.

Fall 55. M. G., 52 J., Kleinhäuslerin, aufgenommen 7. XII. 1905. Am 22. XII. 1904 wegen Cholelithiasis cholecystektomiert. Darauf 2 Monate lang Wohlbefinden, dann traten Schmerzen in der r. Oberbauchbälfte ein, hie und da auch nach den Mahlzeiten, verbunden mit Erbrechen.

Status: Abdomen halbkugelig vorgewölbt, Dilatatio ventriculi. Bei stoßweiser Palpation Magenplätschern, hie und da deutlichste Magensteifung.

19. XII. 1905 Operation. Magen bedeutend dilatiert, der Pylorus stark verengt durch Verwachsungen mit dem Leberrand und dieses mit der Bauchwand.

Gastroenterostomia retrocolica post. anisoperistalt.

Januar 1906. Nachuntersucht. Subjektives Woblbefinden. Keinerlei gastrische Beschwerden.

Juli 1906. Neuerliche gastrische Beschwerden.

Fall 56. T. B., 58 J., aufgenommen 13. XI. 1904. Typische Ulcusbeschwerden seit 24 Jahren. In der letzten Zeit Abmagerung (41 kg).

Status: In der Magengegend nichts Patholog. nachweisbar. $\mathrm{HCl}+$, Milchsäure -. In den Fäces Blut nachweisbar.

Operation 18. XI. 1904. An der kleinen Kurvatur nahe der Kardia eine fünfkronenstückgroße Ulcusnarbe. Gastroenterostomia retrocolica post. anisoperistalt. 
Zur Statistik der Gastroenterostomien bei benignen Magenerkrankungen. $\quad 547$

9. XII. 1904. Nach reaktionslosem Verlauf geheilt entlassen.

Juli 1906. Einigemal Erbrechen, sonst subjektives Wohlbefinden. Körpergewicht $49 \mathrm{~kg}$, gegen 41 vor der Operation.

In der Zeit vom 1. I. 1906 bis 1. X. 1906 wurden an unserer Klinik noch weitere zwanzig hintere Gastroenterostomien ausgeführt. Mitgerechnet in der Berechnung der Mortalitätsverhältnisse konnten diese Fälle zur Bestimmung der Dauerresultate nicht herangezogen werden. Der Grund dafür liegt darin, daß nur in einem geringen Bruchteil der Fälle die zur Beurteilung eines Danerresultates notwendige Zeit von 6 Monaten seit der Operation verstrichen war. $\mathrm{Zu}$ diesen $20 \mathrm{Fällen}$ von hinterer. G.-E. kommt noch ein Fall von vorderer G.-E. (5) mit Enteroanastomose nach Braun, da damals wegen allzu starker Adhäsionen der Magen nicht genügend weit vorgezogen werden konnte, um eine v. Hackersche G.-E. auszuführen. Zwölf von diesen Patienten waren Franen, neun Männer. Die Mortalität betrug 0 Proz. In 14 Fällen war es entweder Ulcus oder eine Ulcusnarbe, in 5 Fällen perigastritische Adhäsionen, bezw. Cholelithiasis, einmal ein Ulcus duodeni, einmal eine Kalilauge Verätzung, die den Anlaß zum operativen Eingreifen boten.

Der Kürze halber sind die Krankengeschichten dieser Fülle in einer Tabelle zusammengestellt.

Wie schon erwähnt, verließen sämtliche Fälle geheilt die Klinik. Nur von drei liegen Nachrichten vor. In einem Falle war bei völligem Wohlbefinden 6 Monate nach der Operation eine Gewichtszunahme von $10 \mathrm{~kg}$, im zweiten 3 Monate p. op. eine solche von $20 \mathrm{~kg}$ zu verzeichnen, einem Patienten ging es nach der Operation schlecht. Es ist dies Fall 4. Bei diesem Patienten war bei der Operation ein kronstúckgroBes Ulcus und eine strahlige Pylorusnarbe gefunden worden; am 31. III. 1906 geheilt entlassen, ließ sich der Mann am 15. V. neuerdings aufnehmen. Starke Schmerzen. Mit Magenspülungen und diätetischem Verfahren besserte sich der Zustand derart, daB von einem neuerlichen, in Frage kommenden Eingriff abgeseben werden konnte. ${ }^{1}$ )

\section{Tabelle V.}

$\left.1 .{ }^{2}\right)$ M., 46 J. - 21 J. - Erbrechen, Schmerzen. - HCl +, Milchsäure - . - Pylorusgegend empfindlich, Kapaz. 2500. - Tumorartige Pylorusnarbe, Pylorus stark verengt.

1) Nach einer Mitteilung des Dr. H. Geiringer in Morva Sct. Martin befindet sich Pat. gegenwärtig vollständig wohl.

2) Bei den einzelnen Fällen kehren folgende Rubriken ständig wieder: Geschlecht u. Alter. - Dauer des Leidens. - Bemerkenswertes aus der Anamnese. - Objektiver Befund. - Operationsbefund. 
2. M., $23 \mathrm{~J} . ~-1 / 2 \mathrm{~J} .-$ Melaena, Abmagerung. -- $\mathrm{HCl}+$, Milchsäure - - Magendilatation, Steifung. Gewicht 53,7 kg. - Hypertrophie der Magenwand, Narbe. Entlassen mit 61,2 kg.

3. M., 31 J. - 6 J. - Oft Melaena, Typische Beschwerden. - $\mathrm{HCl}+$, Milchsäure -. - Druckpunkt. - Adhäsionen.

4. M., 34 J. - 2 J. - Typische Beschwerden. - $\mathrm{HCl}+$, Milchsäure - . Dilatation, kein Tumor. - Kronengroßes Ulcus der kl. Kurvatur, Pylorusnarbe.

5.1) M., $31 \mathrm{~J} .-1 \mathrm{~J}$. - Typische Beschwerden. - $\mathrm{HCl}+$, Milchsäure - - Druckpunkt. Kapaz. 2500. - Starke Adhäsionen, Ulcus der v. Wand.

6. M., $30 \mathrm{~J} .-5 \mathrm{~J} .-$ Typische Beschwerden. - $\mathrm{HCl}+$, Milchsäure - . - Dilatation. Körpergew. $53 \mathrm{~kg}$. - Ulcus duodeni, kronengroß.

7. M., $32 \mathrm{~J}$. - $4 \mathrm{~J}$. - Typische Beschwerden. - $\mathrm{HCl}+$, Milchsäure - . - Plätschern, Dilatation; kein Tumor. - Derbe Adhäsionen des Pylorus. Entz. Tumor.

8. M., 54 J. - 20 J. - Typische Beschwerden. - HCl +, Milchsäure - . - Druckpunkt, Dilatation. - Adhäsionen und Narbe.

9. M., $46 \mathrm{~J} .-3 / 4$ J. - Typische Beschwerden. - $\mathrm{HCl}+$, Milchsäure - . - Plätschern. Kapaz. 3000, - Hartes callöses Pylor-Uleus.

10. W., 53 J. - 3 Mon. - Erbrechen, schwarze Stühle, Ikterus zeitweilig, Darm. - $\mathrm{HCl}+$, Milchsäure - - Tumor der Gallenblase, bedeutende Dilatation. - Cholelithiasis, narbige Ulcusstenose.

11. W., $26 \mathrm{~J}$. - $3 \mathrm{~J}$. - Hämatemesis, Melaena. - HCl +, Milchsäure - . - Empfindlichkeit am Nabel. — Kronenstäckgroßes Ulcus der vord. Pyloruswand.

12. W., 44 J. - 23 J. - Hämatemesis. Tägl. Erbrechen. - $\mathrm{HCl}+$, Milchsäure +. - Leichte Resistenz. Pylorus. Dilatation. - Fünflkronenstückgr. Ulc. am präphyl. Teil.

13. W., 30 J. - 7 Mon. - Sodbrennen. gall. Erbrechen. - HCl -, Milchsäure - . - Undeutliche Resistenz. Dilat. - Cicatricielle Pylorusstenose.

14. W., 17 J. - $3 \mathrm{~J}$. - Zweimal Hämatemesis. - HCl 0, Milchsäure 0. - Dilatation. Plätschern. - Infiltrierendes Pylorus-Ulcus, Stenose.

15. W., 51 J. -1 J. - Häufiges Erbrechen. - $\mathrm{HCl}+$, Milchsäure - Dilatation. Kapaz. 2500. - HaselnußgroBes Entz. Infiltrat des Pylorus.

16. W., 30 J. -3 J. - Typische Ulcusbeschwerden. - $\mathrm{HCl}+$, Milchsäure - . - Dilatation. - Zwickelförmige Einziehung an der Mitte der kl. Kurvatur.

17. W, $23 \mathrm{~J} .-2 \mathrm{~J}$. - Typische Ulcusbeschwerden. - HCl 0 , Milchsäure 0. - Lokaler Druckpunkt, Dilatation. - Kronengroßes Geschwlir der h. Magenwand.

18. W., $29 \mathrm{~J} .-3 \mathrm{~J}$. - Oft Hämatemesis. - $\mathrm{HCl} 0$, Milchsäure 0 . - Druckpunkt. - Zwei Ulcera nahe d. Pylorus, vord. Wand.

1) Vordere Gastroenterostomie. 
Zur Statistik der Gastroenterostomien bei benignen Magenerkrankungen. 549

19. W., 29 J. - 13 J. - 2 Hämatemesis. Tent. sinc. vor 2 Jahren mit $\mathrm{P}$, vor 6 Mon. mit $\mathrm{KHO}$. $\mathrm{HCl}+$, Milchsäure -. - Druckpunkt. - Adhäsionen am Pylorus, stenosierend.

20. W., 29 J. - 9 J. - Typ. Beschwerden. - HCl +, Milchsäure - Plätschern. Dilatat. bis zur Symphyse. Steifung. Kapaz. 3000. Schwiele am Pylorus. Adhäsionen, zahlreiche Ulcusnarben (sehnig).

21. W., 20 J. - 3 J. - Typ. Beschwerden. - HCl +, Milchsäure -. - Dilatation. - Sehr feste Adhäsionen z. Leber, Knickung.

Wien, November 1906.

\section{Literaturverzeichnis.}

i. A bel, Münchner med. Wochenschr. 1899, S. 167.

2. Albert, Wiener med. Wochenschr. 1893, Nr. 1.

3. Bakeš, Langenbecks Archiv 1905.

4. Baracz, Zentralbl. f. Chir. 1892.

5. Bastianelli, ibidem 1894.

6. Beck, Langenbecks Archiv, Bd. 52.

7. Boas, Berliner klin. Wochenschr. 1894.

8. Braun, Zentralbl. f. Chir. 1897.

9. Derselbe, ibidem 1892.

10. Derselbe, ibidem 1899.

11. Ders elbe, Langenbecks Archiv 1899.

12. Derselbe, ibidem, Bd. 45 .

13. Brenner, ibidem, Bd. 69.

14. Derselbe, ibidem 1905 .

15. Brunner, Zentralbl. f. die Grenzgeb. der Chir. u. Med. 1905.

16. Derselbe, Bruns' Beitr., Bd. 40.

17. Derselbe. Korrespondenzbl. f. Schweizer Ärzte 1901.

18. B u omo, Zentralbl. f. Chir. 1896.

19. Burwinkel, Deutsche med. Wochenschr. 1898.

20. Billroth, Langenbecks Archiv, Bd. 39.

21. Beule, Fritz, Bulletin de l'academie Royale de Médecin de Belgue. Bruxelles 1904.

22. Cačkovič, Langenbecks Archiv, Bd. 76.

23. Codivilla, Lo sperimentale 1895.

24. Co Ilin, Zentralbl. f. Chir. 1895.

25. Cohnheim, Deutsche med. Wochenschr. 1900.

26. Courvoisier, Zentralbl. f. Chir. 1883.

27. Czerny-Rindfleisch, Bruns' Beitr., Bd. 9.

28. Czerny, Berliner klin. Wochenschr. 1897.

29. Derselbe, Deutsche med. Wochenschr. 1889.

30. Clairmont, Langenbecks Archiv, Bd. 76.

31. Derselbe, Zentralbl. f. Chir. 1906.

32. Chlumsky, Bruns' Beitr, Bd. 27. 
33. Credé, Zentralbl. f. Chir. 1900.

34. Chaput, Bulletin de la société anat. 1896, S. 349.

35. Crämer, Münchner med. Wochenschr. 1896.

36. Dunin, Berliner klin. Wochenschr. 1894.

37. Dombrowski, Gazeta lekarska 1892.

38. Doyen, Langenbecks Archiv 1898.

39. Debove, Zentralbl. f. Chir. 1902.

40. Dablgren, Zentralbl. f. Chir. 1902.

41. Delaloye, Deutsche Zeitschr. f. Chir. 1906.

42. v. Eiselsberg, Langenbecks Archiv, Bd. 39.

43. Derselbe. ibidem, Bd. 50.

44. Derselbe, Grenzgebiete der Chir. u. Med. 1905.

45. Derselbe, Langenbecks Archiv, Bd. 54.

46. Derselbe, ibidem, Bd. 62.

47. Exner, Zeitschr. f. Heilkunde. 1904.

48. Franke, Sammlung klin. Vorträge 1900, Nr. 270.

49. Fleiner, Archiv für Verdauungskrankheiten, Bd. 3.

50. Derselbe, Münchner med. Wochenschr. 1902.

51. Fischer, Zentralbl. für die Grenzgeb. der Med. u. Chir. 1902.

52. Gosset, Revue de Chir. 1906.

53. Garré, Münchner med. Wochenschr. 1898.

54. Gerulanos, Deutsche Zeitschr. f. Chir., Bd. 57.

55. Hahn, Berl. klin. Wochenschr. 1894.

56. Hansy u. Knauer, Festschr. f. Billroth. 1892.

57. v. Hacker, Zentralbl. f. Chir. 1898, s. 753.

58. Derselbe, ibidem 1885, Nr. 24.

59. Derselbe, Wiener med. Wochenschr. 1887.

60. Haberkant, Langenbecks Archiv 1896.

61. Henle, Zentralbl. f. Chir. 1898.

62. Hofmeister, Bruns' Beiträge 1896.

63. Hirsch, Berl. klin. Wochenschr. 1896.

64. Hahn, Berl. klin. Wochenschr. 1900.

65. Henle, Langenbecks Archir, Bd. 64.

66. v. Hacker, Chirurgische Beiträge aus dem Erzherzogin Sophien-Spital. Wien 1892.

67. Hofman n, Bruns' Beiträge 1906.

68. Fibich, Langenbecks Archiv, Bd. 79.

69. Jedlicka, Zur operativen Behandlung des chronischen Magengeschwürs.

Prag 1894.

70. Jaworski u. Obalinski, Wiener klin. Wochenschr. 1889.

71. Krönlein, Grenzgeb. der Med. u. Chir. 1899, Bd. 4.

72. Derselbe, Bruns' Beiträge, Bd. 15.

73. Derselbe, Zentralbl. f. Chir. 1888.

74. Derselbe, Langenbecks Archiv, Bd. 67.

75. Derselbe, ibidem, Bd. 79.

76. Kaensche, Deutsche med. Wochenschr. 1892.

77. Kausch, Grenzgeb. der Med. u. Chir. 1899.

78. Kaiser, Deutsche Zeitschr. f. Chir., Bd. 61. 
79. Kelling, Langenbecks Archiv, Bd. 62.

S0. Krogius, Zentralbl. f. Chir. 1906.

81. Derselbe, Langenbecks Archiv, Bd. 75.

82. Kelling, Langenbecks Archiv, Bd. 75.

83. Kocher, Enzyklopädie der gesamten Chirurgie.

84. Kapeller, Deutsche Zeitschr. f. Chir., Bd. 40 u. 50.

85. Körte, Langenbecks Archiv, Bd. 63.

86. Kreuzer, Bruns' Beiträge 1906.

87. Kramer, Bruns' Beiträge 1906.

88. Leube, Grenzgeb. der Med. u. Chir. 1887, Bd. 2.

89. Derselbe, Zentralbl. f. klin. Med. 1886.

90. Derselbe, Langenbecks Archiv, Bd. 55.

91. Lennander, Grenzgeb. der Med. u. Chir. 1899, Bd. 4.

92. Lengemand, ibidem 1902.

93. Lau enstein, Deutsche Zeitschr. f. Chir. 1902.

94. Derselbe, Zentralbl. f. Chirurgie.

95. Dersel be, Langenbecks Archiv, Bd. 25.

96. Landerer u. Glücksmann, Grenzgeb. der Chir. u. Med., Bd. I.

97. Langemak, Zentralbl. für die Grenzgebiete 1902.

98. Lücke, Deutsche Zeitschr. f. Chir., Bd. 25.

99. Lorenz, Wiener klin. Wochenschr. 1903.

100. Lieblein-Hilgenreiner, Deutsche Chirurgie, Lief. 46c. 1905.

101. Madelung, Bruns' Beiträge, Bd. 17.

102. Maurer, Langenbecks Archiv 1884.

103. Marwedel, ibidem, Bd. 51.

104. Derselbe, ibidem Bd. 55.

105. Mathes, Zieglers Beiträge, Bd. 13.

106. Maydl, Wiener med. Wochenschr. 1890.

107. Meyer, Medical Record. January 1902.

108. Mikuliez, Grenzgeb. der Med. u. Chir. 1897.

109. Derselbe, Langenbecks Archiv, Bd. 3 .

110. Mintz, Zeitschr. f. klin. Med, Bd. 52.

111. Mündler, Bruns' Beiträge, Bd. 14.

112. Monastyrski, Zentralbl. f. Chir. 1884.

113. v. Noorden, Münchner med. Wochenschr. 1896.

114. Nößke, Deutsche Zeitschr. f. Chir., Bd. 72.

115. Pariser, Deutsche med. Wochenschr. 1895.

116. Payr, Langenbecks Archiv, Bd. 75.

117. Pagenstecher, Deutsche Zeitschr. f. Chir., Bd. 52.

118. Petersen, Deutsche med. Wochenschr. 1899.

119. Derselbe, Bruns' Beiträge, Bd. 29.

120. Derselbe, Langenbecks Archiv, Bd. 62.

121. Petersen u. Machol, Bruns' Beiträge, Bd. 33.

122. Pinner, Zentralbl. f. Chir. 1893.

123. Postnikow, Zentralbl. f. Chir. 1892.

124. Peham, Deutsche Zeitschr, f. Chir., Bd. 22.

125. Perry u. Shaw, On diseases of the duodenum. Guys hospital report 1893.

126. Porges, Wiener klin. Wochenschr. 1897. 
127. Porges, Wiener klin. Rundschau 1902.

128. Rehn, Zentralbl. f. Chir. 1896.

129. Rencki, Grenzgeb. der Med. u. Chir., Bd. 28.

130. Rewizow, Zentralbl. f. Chir. 1899.

131. Rieder, Fortschritte a. d. Gebiete d. Röntgenstrahlen 1905.

132. Riedel, Langenbecks Archiv, Bd. 47.

133. Rosenheim, Zeitschr. f. klin. Med., Bd. 18.

134. Rockwitz, Deutsche Zeitschr. f. Chir., Bd. 25.

135. Robs on, Zentralbl. für die Grenzgeb. 1902.

136. Rutkowski, Zentralbl. f. Chir. 1899.

137. Rydygier, Zentralbl. f. Chir. 1884.

138. Derselbe, ibidem 1885.

139. Derselbe, Langenbecks Archiv, Bd. 25.

140. Salzer, Zeitschr. f. Heilkunde 1899.

141. Schalitta, Zentralbl. f. Chir. 1898.

142. Schloffer, Prager med. Wochenschr. 1901.

143. Schönholzer, Bruns' Beiträge, Bd. 39.

144. Schulz, Grenzgeb. der Med. u. Chir. 1903.

145. Schwarz, ibidem, Bd. 5 .

146. Soupault, Zentralbl. für die Grenzgeb. 1902.

147. Ssapeshko, ibidem 1902.

148. Steinthal, Zentralbl. f. Chir. 1900.

149. Derselbe, Bruns` Beiträge, Bd. 34 .

150. Steudel, Bruns' Beiträge, Bd. 23.

151. Derselbe, Langenbecks Archiv 1898.

152. Stich, Bruns' Beiträge, Bd. 40.

153. Sykow, Arch. f. klin. Chir., Bd. 56.

154. Talma, Zeitschr. f. klin. Med., Bd. 17.

155. Tatsujiro Sato, Langenbecks Archiv, Bd. 73.

156. Titow, Zentralbl. für die Grenzgeb. 1902.

157. Trendl, Bruns' Beiträge, Bd. 39.

158. Tuffier u. Marche, Revue de chirurgie 1897.

159. Trzebicky, Zentralbl. f. Chir. 1899.

160. d'Ursi, ibidem 1893.

161. Vonwyl, Zürich. Inaug.-Diss. 1893.

162. Weber, Zentralbl. für die Grenzgeb. 1902.

163. Wickerhauser, ibidem 1902.

164. Winiwarter, Wiener klin. Wochenschr. 1902, Nr. 52.

165. Wölfler, Zentralbl. f. Chir. 1881.

166. Derselbe, Bruns' Beiträge, Bd. 13.

167. Derselbe, Prager med. Wochenschr. 1896.

168. Derselbe, Berliner klin. Wochenschr. 1896. 